\title{
Yeast cell factories for fine chemical and API production Beate Pscheidt ${ }^{1}$ and Anton Glieder*1,2
}

\begin{abstract}
Address: ${ }^{1}$ Research Centre Applied Biocatalysis GmbH, Petersgasse 14/3, 8010 Graz, Austria and ${ }^{2}$ Institute of Molecular Biotechnology, Graz University of Technology, Petersgasse 14/2, 8010 Graz, Austria
\end{abstract}

E-mail: Beate Pscheidt - beate.pscheidt@a-b.at; Anton Glieder* - a.glieder@tugraz.at

${ }^{*}$ Corresponding author

Published: 07 August 2008

Microbial Cell Factories 2008, 7:25 doi: 10.1/86/1475-2859-7-25
Received: 26 May 2008

Accepted: 7 August 2008

This article is available from: http://www.microbialcellfactories.com/content/7/1/25

(C) 2008 Pscheidt and Glieder; licensee BioMed Central Ltd.

This is an Open Access article distributed under the terms of the Creative Commons Attribution License (http://creativecommons.org/licenses/by/2.0), which permits unrestricted use, distribution, and reproduction in any medium, provided the original work is properly cited.

\begin{abstract}
This review gives an overview of different yeast strains and enzyme classes involved in yeast wholecell biotransformations. A focus was put on the synthesis of compounds for fine chemical and API (= active pharmaceutical ingredient) production employing single or only few-step enzymatic reactions. Accounting for recent success stories in metabolic engineering, the construction and use of synthetic pathways was also highlighted. Examples from academia and industry and advances in the field of designed yeast strain construction demonstrate the broad significance of yeast whole-cell applications. In addition to Saccharomyces cerevisiae, alternative yeast whole-cell biocatalysts are discussed such as Candida sp., Cryptococcus sp., Geotrichum sp., Issatchenkia sp., Kloeckera sp., Kluyveromyces sp., Pichia sp. (including Hansenula polymorpha $=$ P. angusta), Rhodotorula sp., Rhodosporidium sp., alternative Saccharomyces sp., Schizosaccharomyces pombe, Torulopsis sp., Trichosporon sp., Trigonopsis variabilis, Yarrowia lipolytica and Zygosaccharomyces rouxii.
\end{abstract}

\section{Background}

The advent of yeast whole-cell biocatalysis coincided with the development of first technologies for the human society. Some thousand years $\mathrm{BC}$, when organized agriculture had appeared, the development of yeast-based technology started. Today, artistic records (e.g. in tombs of wealthier members of the ancient Egyptian society) and archaeological data provide an insight into the daily life in ancient Egypt $[1,2]$ and teach us that bread and also beer were central parts of the Egyptian's diet [3]. However, no more than approximately 200 years ago, leading scientists recognized yeasts as the cause of fermentation and started to examine them because of their economic importance and one morphologic advantage compared to some other microorganisms, their large cells [4]. Understanding the scientific basis for alcoholic fermentation was financially well supported by the alcoholic fermentation industries and governments at that time. Basically, research on yeasts greatly contributed to the development of microbiology, biochemistry and also biocatalysis. Berthelot's and Emil Fischer's research results on the utilization of different sugars by yeasts were central to studies on enzymes and their specificity. Especially Fischer's lock and key model published in 1894 [5] provided the basis for subsequent concepts. These include for example the theory about the enzyme-substrate complex developed by Henri [6] and Michaelis \& Menten [7], respectively, Haldane's concept of substrate activation representing the idea of selective binding energy which leads either to transition state stabilization or substrate destabilization [8], and the induced fit theory described by Koshland $[9,10]$. Early yeast research, which was comprehensively reviewed by Barnett [4], also contributed to basic biochemical knowledge including the understanding of metabolic pathways, Monod's concepts of enzyme induction[11] and basic findings on cell cycles $[12,13]$. 
Most of this early research was based on Saccharomyces cerevisiae and therefore, the term 'yeast' was and is often taken as a synonym for $S$. cerevisiae. However, yeasts belong to a group of eukaryotic microorganisms, predominantly unicellular and phylogenetically quite diverse [14]. They are assigned to two taxonomic classes of fungi, the ascomycetes and the basidiomycetes $[14,15]$. Their classification is mostly based on phenotypic characters such as morphology, the ability to utilize various exogenous compounds and modes of vegetative reproduction, namely budding or fission. Some yeasts also form sexual states which differ from those of other fungi as they are not enclosed in fruiting bodies [15]. At the end of the $20^{\text {th }}$ century molecular methods have become increasingly popular in order to estimate genetic relation among yeasts. Recently, Hibbett et al. [16] attempted to create a consensus higher-level classification for the Fungi for general use. This broad-based consensus classification was necessary in order to prevent confusion and loss of information as caused by repetitive renaming of several yeast strains in the past [17]. An overview of yeast genera was provided by Walker [18] or Boekhout and Kurtzman [15,19], for example. A comprehensive phylogenetic relationship among sequenced fungal genomes, including more than 20 yeast genomes, was recently depicted by Scannell et al. [20].

Although yeasts, especially Saccharomyces cerevisiae, have been employed in synthetic organic chemistry since the beginning of the $20^{\text {th }}$ century [21-23], scientists devoted to classical organic chemistry often hesitated to consider biological systems for their synthetic problems [24]. In the 1970s, biocatalysis started booming and up to now the number of publications on biotransformations has been rising exponentially. Remarkable findings led to a better understanding of biological systems and consequently to their increased application for chemical conversions, especially in the field of organic synthesis [25].

In general, two major synthetic technologies based on biocatalytic reactions were described, namely 'fermentation' and 'enzymation' (alternative names for 'enzymation': 'microbial transformation', 'microbial conversion', 'biotransformation', 'bioconversion') [24,25]. Fermentation was considered to be a biological method resulting in products which are the result of the complex metabolism of microorganisms starting with inexpensive simple carbon and nitrogen sources. As a consequence, living or even growing cells were a prerequisite for this technology and fermentation was regarded to always result in natural products [25]. On the other hand, enzymation was specified not to necessarily require living cells, as cells were only important for the enzyme's production and were themselves regarded as 'simple bag of enzymes or catalysts' [25]. Furthermore, enzymation was described to be a one or few-step conversion of a more complex substrate into a product $[24,25]$. However, Yamada and Shimizu [25] already stated that it was not always possible to clearly distinguish between the two categories.

In recent years, the way for the generation of designed microorganisms was paved by an increasing number of sequenced genes and even whole genomes, new bioinformatic tools providing the basis for analyzing this wealth of information, biochemically well-characterized biosynthetic pathways and well-established and facile genetic engineering techniques. These approaches include for example, the construction of synthetic pathways for the production of structurally complex, natural products like isoprenoids or polyketides and novel variations thereof. Furthermore, even minimum genome factories could enter the field of biocatalysis in future. Currently, first examples of such cell factories are created in which unnecessary or harmful genes are deleted and only genes necessary for industrial production are present [26]. For this approach, up to now, three species were selected, namely two bacteria (Escherichia coli [27] and Bacillus subtilis [28]), and the fission yeast Schizosaccharomyces pombe [29]. With these developments in mind, one has to admit that the idea of whole-cell biocatalysts being 'black boxes' already started to fade.

The following chapters will now give an overview of different yeast strains and enzyme classes involved in yeast whole-cell biocatalysis. We will provide examples from academia and industry and especially focus on recent advances in the field of designed yeast strains for whole-cell biocatalytic applications. Thereby, we will also include synthetic pathways to structurally complex compounds, a methodology which lies in between classical 'fermentation' and 'enzymation'. Thus, we will include both, one- and multi-step enzymatic reactions in a native or engineered environment, starting with simple or complex substrate molecules.

\section{Review \\ I. Chemical reactions catalyzed by wild-type yeast whole-cell biocatalysts}

Especially baker's yeast (= Saccharomyces cerevisiae) was regarded to be ideal for chemists looking for a stereoselective biocatalyst, which should eventually lead to chiral intermediates in the synthesis of enantiomerically pure compounds [30]. It is nonpathogenic, inexpensive, simple to grow at laboratory and large scale and the cells can be stored indefinitely in dried form [24]. For chemical synthesis, however, the chemical repertoire of 
yeast whole-cell biocatalysts is of major importance. In the following, an overview is given, outlining the main enzymatic reactions performed by wild-type yeast strains, and positive and negative aspects of these whole-cell biocatalysts are discussed.

\section{I.I Reduction of $\mathrm{C}=\mathrm{O}$-bonds}

The asymmetric reduction of carbonyl-containing compounds by yeast, in particular Saccharomyces cerevisiae, depicts probably the most thoroughly investigated class of whole-cell biotransformations. One of the first reports on this topic was the reduction of furfural to furfuryl alcohol by Windisch [31] and Lintner [32] at the beginning of the $20^{\text {th }}$ century. The first comprehensive overview of reduction reactions catalyzed by yeast was published in 1949 [33]. Since that time, many different substrates containing carbonyl moieties were subjected to yeast bioreduction and the most important achievements were summarized in reviews and book chapters, partly focusing on Saccharomyces cerevisiae $[30,34,35]$ but also on biocatalysts in general, including alternative yeasts $[24,25,36-43]$. The investigated substrate spectrum is huge, including a variety of functional groups as substituents of the ketone moiety (for example heterocyclic-, hydroxyl-, sulfur-, cyano-, and azido-groups, or different halogenides) and even derivatives such as silylor germyl-groups were found to be accepted [24]. Generally, Saccharomyces cerevisiae reduces simple aliphatic and aromatic ketones according to Prelog's rule [44] resulting in the corresponding (S)-alcohols [45] (Figure 1). However, this should not always be generalized and caution should be exercised in particular, when Prelog's rule is applied to whole cells [34].

A major advantage of whole-cell (redox)-biocatalysts is the availability of all the necessary cofactors and metabolic pathways for their regeneration. Furthermore, cheap carbon sources (e.g. glucose, saccharose) can be employed as auxiliary substrates. Finally, the actual biocatalyst and cofactors are well protected within their natural cellular environment which makes the catalytic system more stable [24]. However, employing wild-type yeast strains as whole-cell biocatalysts also includes distinct drawbacks: Most of the interesting substrates are non-natural and toxic to living organisms. Therefore, they must be used in diluted systems at low concentrations (mostly $\leq 0.3 \%$ per volume) $[24,46]$. Only small fractions of the auxiliary substrate are used for cofactor recycling, the majority is metabolized. This results in large amounts of biomass and by-products which impede product recovery tremendously, especially if the product is not secreted to the reaction medium. Transport phenomena into and out of the cell could be encountered which may even influence specificity $[24,46]$. Eventually, comparable results are only possible if exactly the same culture is used for repetitive biotransformations since different strains of the same microorganism could have different specificities [24,46]. Another major limitation of wild-type yeast strains is the presence of a large number of different dehydrogenases with overlapping substrate specificities but opposite stereoselectivities [47]. The elucidation of the complete genome sequence of Saccharomyces cerevisiae [48,49] finally made scientists aware of the huge variety of available oxidoreductases. Earlier, empirical findings helped to develop methods to improve the selectivity of yeast whole-cell biotransformations. These techniques included substrate modification [50], changes in cultivation conditions or the application of different carbon sources [51], the use of inhibitors [52] or the use of twophase systems $[53,54]$. Recently, also water immiscible ionic liquids were used as biocompatible solvents for yeast whole-cell biocatalysis in order to provide a substrate reservoir and an in situ extracting agent to increase chemical yields [55].


Sequence rule order of large $>$ small is assumed.

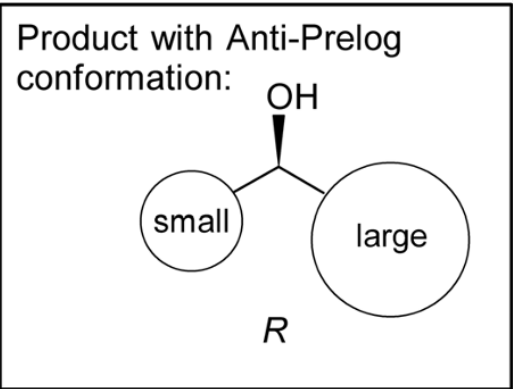

Figure I

Asymmetric reduction of ketones according to Prelog's Rule [44]. 
If these techniques were not successful, alternative microorganisms had to be screened. In addition to Saccharomyces cerevisiae also alternative yeasts were found which provided valuable biocatalysts for asymmetric carbonyl reduction. Some were efficient enough to be employed for industrial applications by different companies (Table 2 and Additional File 2, Section 2).

Some recent advances in the biocatalytic reduction of carbonyl-containing compounds are summarized in Table 1 (Additional file 1) and include for example the finding of new activities for Yarrowia lipolytica [56]. Lagos et al. [56] screened different yeast strains for the enantioselective production of a halohydrin precursor for (S)-propranolol synthesis. Yarrowia lipolytica 1240 (Spanish type culture collection CECT, Valencia) resting cells gave the 'anti-Prelog'-enantiomer (S)-1-chloro-3-(1naphthyloxy)propan-2-ol with $87 \%$ yield and $99 \%$ ee. In addition, Pichia mexicana 11015 (CECT, Valencia) resting cells were found to give $85 \%$ yield and $95 \%$ ee for the (R)-enantiomer. Dehli and Gotor [57] discovered that resting cells of Saccharomyces montanus CBS 6772 performed the bioreduction of 2-oxo cyclopentane carbonitriles to the corresponding cis-hydroxynitriles in $93 \%$ ee, and high de and chemical yields.

As cheap alternative, Saccharomyces cerevisiae is still quite often used for laboratory-scale bioreductions. Enders et al. [58] described the efficient asymmetric total synthesis of (-)-callystatin A, a potent cytotoxic polyketide from a marine sponge, employing a combination of chemical and biocatalytic methods. Therefore, tert-butyl 6-chloro-3,5-dioxohexanoate was subjected to dried baker's yeast in a biphasic system (water/XAD-7 adsorber resin) and was regio- and enantioselectively reduced to the (5R)-hydroxy keto ester in $94 \%$ enantiomeric excess [58]. Furthermore, Bertau and Burli [59] reported the application of Saccharomyces cerevisiae cells for the synthesis of $(2 S, 5 S)$-hexanediol. Glucose was used as auxiliary substrate for cofactor regeneration and with $25 \mathrm{mmol}$ of hexanedione as substrate complete conversion with > 99\% ee, 96\% de and 75\% yield was achieved. Servi and coworkers [60] showed that whole cells of Geotrichum candidum CBS 233.76 (95\% yield, > 98\% ee; $4 \mathrm{~g} / \mathrm{L}$, with absorbing resin Amberlite XAD-1180) and Rhodotorula mucillaginosa CBS 2378 (88\% yield, > 99\% ee; $1 \mathrm{~g} / \mathrm{L}$ ) reduced 3,4-dichlorophenacyl chloride to the $(S)$ - and $(R)$-alcohol, respectively.

Matsuyama et al. [61] screened several yeast strains for the large scale production of $(R)$-1,3-butanediol, as the productivity of already reported asymmetric microbial reduction processes (for example with $S$. cerevisiae) was not satisfactory. Starting with 4-hydroxy-2-butanone, Candida arborea IAM 4147 and Issatchenkia scutulata IFO
10070 showed excellent ee (99\%) but low yield, whereas Kluyveromyces lactis IFO 1267 gave high yield and good enantiomeric excess $(93 \%)$ for $(R)-1,3$-butanediol. In contrast, Candida parapsilosis IFO 1396 performed the best for (S)-1,3-butanediol production (98\% ee, 60\% yield). In recent times, a new yeast isolate, namely Candida tropicalis PBR-2 MTCC 5158 was reported to enantioselectively reduce acetophenone and several substituted analogues to the corresponding $(S)$-alcohols with an enantiomeric excess of $>97 \%$, mostly even $>$ $99 \%$ [62]. As the natural aroma compounds 2-phenylethanol (2-PE) and 2-phenylethylacetate (2-PEAc) are of high industrial value, Etschmann and Schrader [63] lately improved their production by employing Kluyveromyces marxianus CBS 600 for a growth-associated product formation starting with L-phenylalanine. 26.5 $\mathrm{g} \mathrm{L}^{-1}$ 2-PE and $6.1 \mathrm{~g} \mathrm{~L}^{-1}$ 2-PEAc were obtained in the organic phase which consisted of polypropylene glycol 1200, used as in situ extractant. This corresponded to space-time yields of 0.33 (2-PE) and $0.08 \mathrm{~g} \mathrm{~L}^{-1} \mathrm{~h}^{-1}$ (2-PEAc) surpassing the results of a previously reported S. cerevisiae process (Table 1; Additional File 1) [64]. Finally, Nakamura et al. [41] reviewed the use of Geotrichum candidum whole-cell preparations for the synthesis of chiral secondary alcohols with high enantioselectivities (up to > 99\% ee).

In addition to these and also future findings in the field of selective yeast carbonyl-bioreductions, a strong trend for the construction of so-called 'designer-bugs' namely whole-cell biocatalysts co-expressing all required enzymes can be observed [65]. Most often E. coli is employed as recombinant host [66-69] due to the wealth of oxidoreductases found in yeasts, in particular, in Saccharomyces cerevisiae. Nowadays, the increasing number of annotated DNA sequences helps to identify enzymes involved in bioreductions and provides the information needed for the rational design of recombinant whole-cell biocatalysts [47].

\subsection{Reduction of C=C-bonds}

In 1933, the first flavin-dependent redox enzyme was discovered in Brewer's bottom yeast by Warburg and Christian [70]. Enzymes of this family are also known as 'old yellow enzymes' because of their color derived from the flavin cofactor. Typical substrates $[24,71]$ are alkenes which are 'activated' by electron-withdrawing substituents. Such substrates are reduced at the expense of NAD $(\mathrm{P}) \mathrm{H}$ leading to enantiomerically pure alkanes. Thereby up to two chiral carbon centers are created (Figure 2).

In the past, most asymmetric bioreductions of activated $\mathrm{C}=\mathrm{C}$ bonds employing enoate reductases were performed with whole cells, since problems with external 
Table I: Examples of wild-type yeast whole-cell biocatalysts for the reduction of $\mathrm{C}=\mathrm{O}$ bonds and comparison to $\mathrm{S}$. cerevisiae, if provided

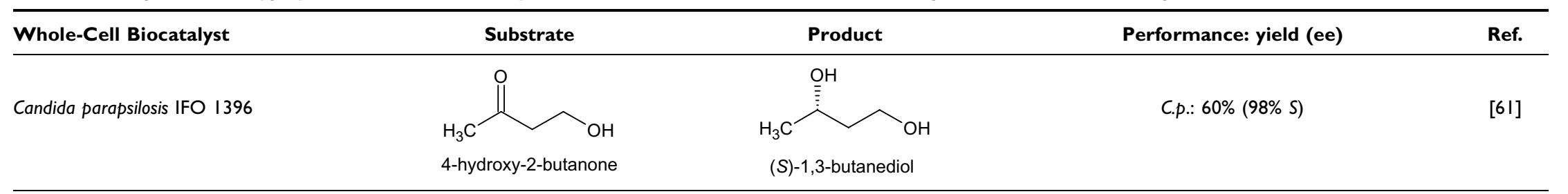

Candida arborea IAM 4147<smiles>C[C@@H](O)CCO</smiles>

Issatchenkia scutulata IFO 10070

(R)-1,3-butanediol

C.a.: $37 \%(99 \% R)$

l.s.: $48 \%(99 \% R)$

Kluyveromyces lactis IFO I267

$(R)-1,3-$ butanediol

K.I.: $99 \%(93 \% R)$

Candida tropicalis PBR-2 MTCC 5158

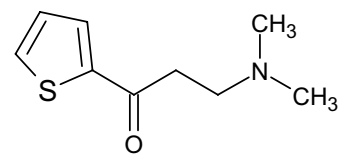

$\mathrm{N}, \mathrm{N}$-dimethyl-3-keto-3-(2-thienyl)-

1-propanamine

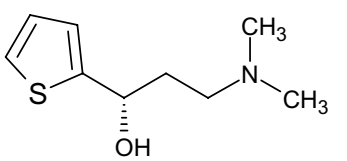

[62]

(S)-N,N-dimethyl-3-hydroxy-

3-(2-thienyl)-1-propanamine

Geotrichum candidum CBS 233.76 with Amberlite XAD-II80
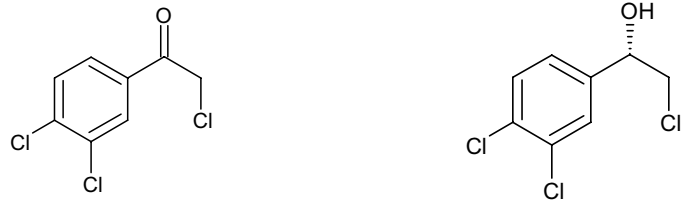

G.c.: $95 \%(>98 \%$ S)

3.4-dichloro- $\alpha$-chloroacetophenone

$s$

Rhodotorula mucillaginosa CBS 2378

Saccharomyces cerevisiae



$\mathrm{Cl}$

R.m.: $88 \%(>99 \% R)$

S.c.: $95 \%(4 \mid \% R)$

Saccharomyces montanus CBS 6772

Saccharomyces cerevisiae (Type II from Sigma)

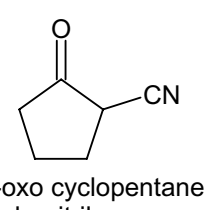

carbonitrile

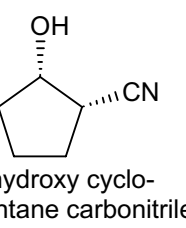

S.m.: ee cis $=93 \%(I S, 2 S)$

cis:trans $=96: 4$ 
Table I: Examples of wild-type yeast whole-cell biocatalysts for the reduction of $\mathrm{C}=\mathrm{O}$ bonds and comparison to $\mathrm{S}$. cerevisiae, if provided (Continued)

Saccharomyces cerevisiae (dried baker's yeast)

2,5-hexanedione $(2 S, 5 S)$-hexanediol

Pichia mexicana $\mathrm{CECT}^{\mathrm{c}}$ II015

Saccharomyces cerevisiae $\mathrm{CECT}^{\mathrm{c}} 1317$
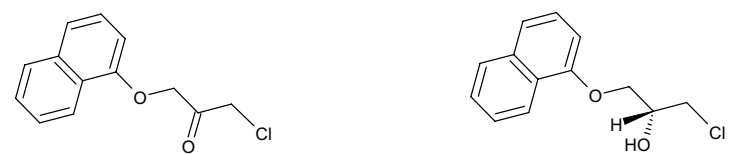

P.m.: $85-86 \%(95 \%$ R)

1-chloro-3-(1-naphthyloxy)propan-2-one

(R)-1-chloro-3-11-naphthyloxy)propan-2-ol

S.c.: $48 \%(75 \% R)$

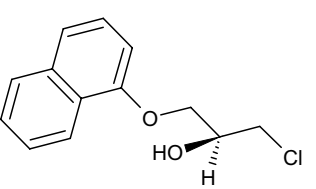

Y.I.: $87-88 \%(99 \%$ S)

Yarrowia lipolytica $\mathrm{CECT}^{\mathrm{C}} 1240$

(S)-1-chloro-3-(1-naphthyloxy)propan-2-o

Saccharomyces cerevisiae (Type II, Sigma)

S.c.: $32 \%(83 \%$ S)

Kluyveromyces marxianus CBS 600

Saccharomyces cerevisiae GIV 2009
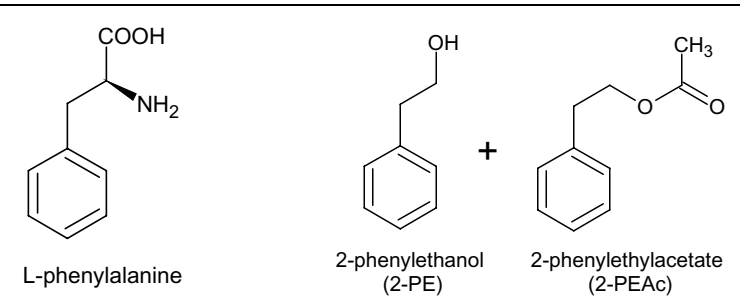

K.m.: 2-PE: $26.5 \mathrm{~g} \mathrm{~L}^{-1}$ in org. phase

STY: $0.33 \mathrm{~g} \mathrm{~L}^{-1} \mathrm{~h}^{-1}$

[63]

2-PEAc: $6.1 \mathrm{~g} \mathrm{~L}^{-1}$ in org. phase ${ }^{\mathrm{e}}$ STY: $0.08 \mathrm{~g} \mathrm{~L}^{-1} \mathrm{~h}^{-}$

(2-PEAc) S.c.: 2-PE: $24.0 \mathrm{~g} \mathrm{~L}^{-1}$ in org. phase
STY: $0.14 \mathrm{~g} \mathrm{~L}^{-1} \mathrm{~h}^{-1}$

${ }^{\mathrm{a}}$ conv. = conversion; ${ }^{\mathrm{b}}$ baker's yeast from Distillerie Italiane, Eridania group; ${ }^{\mathrm{C} S p a n i s h}$ type culture collection CECT, Valencia; ${ }^{\mathrm{d}}$ The wild type strain S. cerevisiae Giv 2009 was from

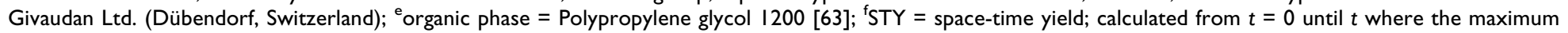
product concentration was reached; 'organic phase = oleic acid [64]. 

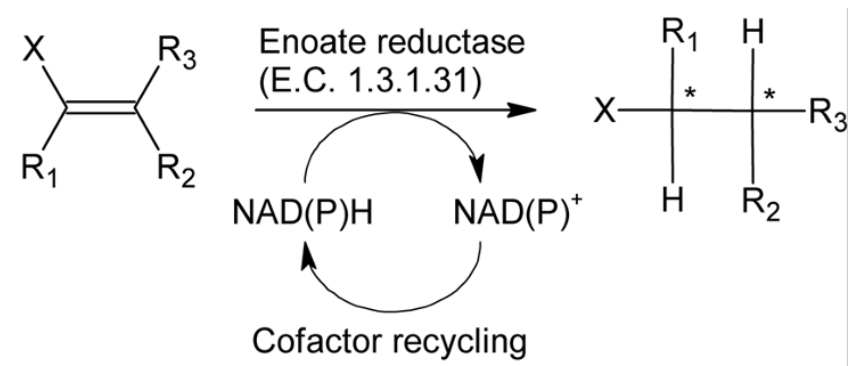

Figure 2

Enoate reductases perform the $\mathrm{NAD}(\mathrm{P}) \mathrm{H}$-dependent, asymmetric bioreduction of activated $\mathrm{C}=\mathrm{C}$ bonds. A cofactor recycling system is required for an economic process. Asterisks (*) indicate chiral centers, $X$ depicts an activating group such as carbonyl-, carboxyl-, imide- or nitro-group [24,7I].

cofactor recycling and the enzyme's sensitivity to traces of oxygen were encountered [24,72]. With whole-cell bioreductions often excellent stereoselectivities were achieved. However, chemoselectivity is often poor, regarding especially competitive $\mathrm{C}=\mathrm{C}$ - and $\mathrm{C}=\mathrm{O}$-bond reductions. Whole-cells do not only provide enoate reductases but also alcohol dehydrogenases which both depend on the same nicotinamide cofactor. Uncoupling is hardly possible and the relative rates of alcohol dehydrogenases are comparable to those of enoate reductases leading to undesired by-products [71]. Nevertheless, successful examples for asymmetric bioreductions of $\alpha, \beta$-unsaturated ketones exist, for example, with $S$. cerevisiae cells: Careful reaction control during oxoisophorone bioreduction led to the main product $((R)$-2,2,6-trimethylcyclohexane-1,4-dione) in $>80 \%$ yield. The unwanted by-products were kept to a minimum. The product - also known as $(R)$-levodione was produced on a $13 \mathrm{~kg}$-scale [73]. It is industrially used for 3-hydroxycarotenoid production [74] (Table 2 and Additional File 2).

In general, the most prominent whole-cell biocatalyst employed was again baker's yeast ( $S$. cerevisiae) which was tested with a great variety of differently substituted alkene substrates, such as e.g. different $\alpha, \beta$-unsaturated nitroalkenes. It tolerated many different functional groups like alkyls and (substituted) aryls attached to the nitroalkene moiety $[75,76]$. However, also alternative yeasts were described to be active. Geotrichum candidum [77], Rhodotorula rubra [78] and Rhodosporidium sp. [78] were found to possess enoate reductases, active for diverse non-natural $\alpha, \beta$-unsaturated carbonyl- and carboxyl-compounds, respectively [71]. Candida sp., Rhodotorula sp. and Torulopsis sp. were also shown to be active on $\alpha, \beta$-unsaturated nitroalkenes [79]. Currently, the use of isolated enzymes or the construction of 'designer bugs' provides the possibility to reduce side reactions significantly. Desired yeast enoate reductases (e.g. from Saccharomyces cerevisiae [80], Saccharomyces carlsbergensis [81] or Candida macedoniensis [82]) were recently cloned and overexpressed in E. coli. Kataoka et al. [82] even coexpressed glucose dehydrogenase $(\mathrm{GDH})$ for efficient cofactor regeneration. More details were outlined and reviewed by Faber [24] and Stuermer et al. [71], respectively.

\section{I.3 Oxidation and racemization reactions}

Yeast alcohol oxidases were shown to be responsible for the oxidation of methanol and other primary alcohols [83-85]. However, they did not oxidize secondary alcohols. In general, reports on oxidation reactions performed by yeasts are quite rare. Considering especially the oxidation of secondary alcohols, one has to recognize that instead of creating a chiral center, it is 'destructed'. The reaction is therefore regarded to be of limited synthetic use except for the regioselective oxidation of polyols where chemical methods are often inadequate [24]. However, the recent, increasing demand for 'deracemization processes', leading to a single stereoisomer in $100 \%$ yield, evoked the need for 'clean' racemization protocols [86]. Not to forget, the oxidation of sulfides can result in chiral sulfoxides which have been widely used in organic synthesis as asymmetric auxiliary groups to control the stereochemical outcome of the reaction at nearby centers $[87,88]$.

In 1979, Patel et al. [89] described the application of cell suspensions of Candida utilis ATCC 26387, Hansenula polymorpha ATCC 26012, Pichia sp. NRRL-Y-11328, Torulopsis sp. and Kloeckera sp. for the oxidation of secondary alcohols. 2-Propanol, 2-butanol, 2-pentanol, and 2-hexanol were oxidized to the corresponding methyl ketones. Furthermore, Saccharomyces cerevisiae was reported to catalyze the selective oxidation of sulfides to sulfoxides. Beecher et al. [90] investigated the oxidation of $p$-tolyl sulfide to the R-sulfoxide (92\% ee) which was used for the preparation of the mevinic acid-type hypocholestemic agent. Buist et al. [91] employed baker's yeast for the enantioselective sulfoxidation of a fatty acid analogue ( $70 \%$ ee). In this study, the authors presumed that a desaturase could be responsible for the transformation, but did not verify it.

In order to satisfy needs for sophisticated racemization protocols, Nestl et al. [86,92] screened various microbial cells for the biocatalytic racemization of functionalized $\alpha$-hydroxyketones. Although whole lyophilized cells of Geotrichum candidum DSM 6401, Candida parapsilosis DSM 70125, or Kluyveromyces lactis DSM 3795 were 
Table 2: Industrial biotransformations [74] employing wild type yeast whole-cell biocatalysts ordered by E.C. numbers

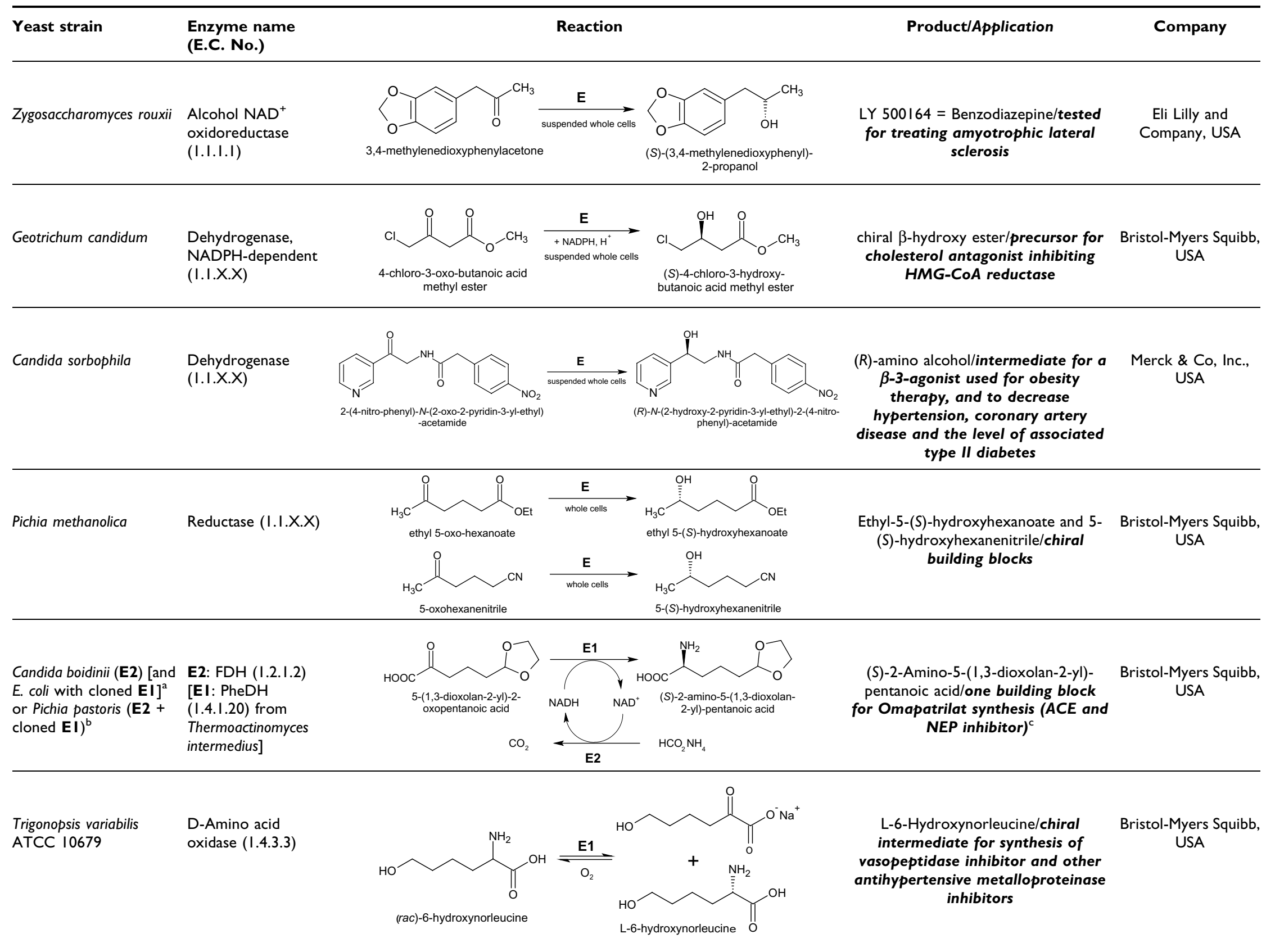


Table 2: Industrial biotransformations [74] employing wild type yeast whole-cell biocatalysts ordered by E.C. numbers (Continued)

\begin{tabular}{lll}
\hline Baker's yeast $(=$ & Reductase (I.X.X.X) \\
Saccharomyces cerevisiae) & $\begin{array}{c}\text { The corresponding dione is an } \\
\text { intermediate for the synthesis of } \\
\text { natural 3-hydroxycarotenoids } \\
\text { (e.g. cryptoxanthin, zeaxanthin) and } \\
\text { other terpenoid compounds. }\end{array}$
\end{tabular}

Cryptococcus laurentii EI: Lactamase

(EI) [and Achromobacter (3.5.2.1I) and [E2:

obae (E2) $]^{\mathrm{a}}$

Racemase

(5.I.I.I5) $]^{\mathrm{a}}$

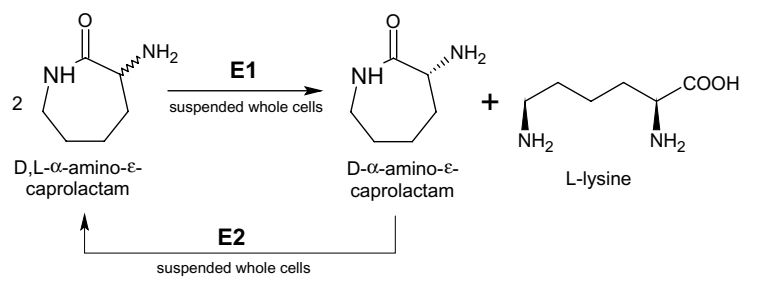

L-Lysine/nutrient and food supplement

Toray Industries Inc., Japan
PAC $\rightarrow$ ephedrine and pseudoephedrine/treatment of asthma, hay fever, and used for bronchodilating agent and decongestant
Krebs Biochemicals \& Industries Ltd., India decarboxylase (4.I.I.I)

<smiles>[C+]=CC</smiles>

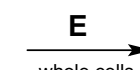

$\overrightarrow{\text { whole cells }}$ acetaldehyde benzaldehyde
(1R)-phenylacetylcarbinol (PAC)
(R)- $\beta$-Hydroxy-n-butyric acid and Kanegafuchi $(R)$ - $\beta$-Hydroxy-isobutyric acid/chiral Chemical Industries synthons for carbapenem intermediate and captopril (ACE-inhibitor) ${ }^{c}$, respectively



\section{Rhodotorula rubra \\ L-Phenylalanine ammonia-lyase (4.3.1.5)}

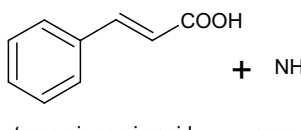

trans-cinnamic acid

ammon

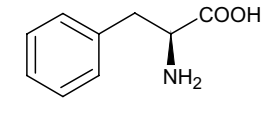

L-phenylalanine
L-phenylalanine/artificial sweetener aspartame, parenteral nutrition,

Genex Corporation, chiral building block for Rutamycin

$$
B \text { synthesis }
$$

${ }^{\mathrm{a}}$ Bacterial whole-cell biocatalyst; ${ }^{\mathrm{b}}$ In this case, also engineered $\mathrm{P}$. pastoris cells were employed; ${ }^{\mathrm{C}} \mathrm{ACE}=$ angiotensin-converting enzyme; $\mathrm{NEP}=$ neutral endopeptidase. 
identified to racemize a variety of the employed target substrates, the activities of yeast strains were modest compared with bacteria and fungi. Traces of diketones as 'side products' let them assume that dehydrogenase enzymes were responsible for the racemization reaction [86].

Matsuyama et al. [61] performed the oxidative kinetic resolution for the large-scale production of $(R)-1,3-$ butanediol employing Candida parapsilosis IFO 1396. Starting with $20 \mathrm{~kg}$ (rac)-1,3-butanediol, $258 \mathrm{~kg}$ cells, $465 \mathrm{~kg}$ water and $7.5 \mathrm{~kg}$ calcium carbonate resulted in $\sim 3.1 \mathrm{~kg}$ of $(R)-1,3$ butanediol in high chemical ( $99 \%)$ and optical purity ( $94 \%$ ee). A subsequent enzyme purification step elucidated (S)-1,3-butanediol dehydrogenase $(\mathrm{CpSADH})$ to be responsible for producing $(R)$ 1,3-butanediol from the racemate. CpSADH was then also overexpressed in E. coli yielding in increased specific activities and a strain with good racemization properties for the production of $(R)$-1,3-butanediol (95\% yield, $94 \%$ ee) without the need for cofactor regeneration. Recently, Titu and Chadha [93] described the biocatalytic preparation of optically pure alkyl 3-(hetero-2-yl)-3hydroxypropanoates by deracemization. Candida parapsilosis ATCC 7330 was employed and various optically pure products resulted in high ee (89-99\%) and yields (58-75\%). These compounds represent important chiral intermediates for the synthesis of pharmaceuticals such as duloxetine, tetrahydropyrans or heteroarylaminoalkanols, among others.

In most cases, however, the enzyme or enzyme-set catalyzing racemization reactions remains unknown. Their identification and employment in a non-natural environment (biotransformation with solubilized or immobilized enzyme(s) or a recombinant whole-cell biocatalyst) could further reduce the amount of undesired side-reactions, improve optical purities and also provide a platform for enzyme engineering approaches. Examples of 'yeast designer bugs' with enzymes for chiral sulfoxide production are given in Section 3.

\subsection{Hydrolase reactions}

Saccharomyces cerevisiae was also tested for hydrolase reactions. However, first yeast-catalyzed deacylation reactions were regarded to be undesired side-reactions when Mamoli et al. [94] was studying whole cells of baker's yeast for the stereoselective reduction of estrogen ester. Later, the whole variety of hydrolysis reactions performed by Saccharomyces cerevisiae was investigated and comprehensive reviews on the properties of proteinases [95], lipases and esterases [34] were given. What was encountered quite fast was the complex reaction control when whole microbial cells were employed [24].
To overcome the problems resulting from the metabolism of fermenting Saccharomyces cerevisiae, lyophilized resting cells were employed. Thus, for example the acetate of pantolactone - the chiral precursor for vitamin $\mathrm{B}_{5}$ synthesis - was nicely resolved [96]. In addition, differently substituted 1-alkyn-3-yl acetates were converted with high ee (91-96\%) to the corresponding $(S)$ alcohols and acceptable enantioselectivities (E 46-100) were reached [24].

Many yeast hydrolases especially from Candida sp. were employed in industrial biotransformations. However, they were mostly used as immobilized enzyme preparations due to perturbing unspecific hydrolases available in whole cells. Only were other fungal and some bacterial strains industrially employed as whole cells for hydrolase reactions [74]. Immobilized whole cells of Fusarium oxysporum were for example used for the production of D-pantoic acid starting with ( $\mathrm{rac}$ )-pantolactone [97]. Suspended whole cells of Comamonas acidovorans catalyzed the conversion of ( $\mathrm{rac}$ )-2,2dimethylcyclopropanecarboxamide to the corresponding $(R)$-carboxylic acid and the $(S)$-carboxamide remained [98]. In addition, whole cells of Bacillus brevis [99,100], Pseudomonas sp. [74] and Arthrobacter sp. [101] were employed i.a. for hydantoinase catalyzed reactions.

Furthermore, Rhodotorula sp., Rhodosporidium sp. and Trichosporon sp. were found to give best enantioselectivities for the hydrolysis of monosubstituted oxiranes. All showed preferred enantiopreference for the $(R)$-form and regioselectivity for the sterically less hindered carbon atom [24]. Recently, again a highly selective epoxide hydrolase from Rhodosporidium paludigenum CBS 6565 was observed during whole-cell biotransformations, subsequently cloned and further characterized [102].

\section{I.5 Formation of C-C-bonds}

From a synthetic point of view, carbon-carbon bond forming reactions are highly interesting as new asymmetric carbon centers can be formed. However, this type of yeast whole-cell biotransformation was and is limited to only a few examples $[30,34]$. The most prominent and industrially employed acyloin condensation performed by Saccharomyces cerevisiae yields in the formation of (1R)-phenylacetyl carbinol, a chiral synthon of Dephedrine (Table 2 and Additional File 2). Crout et al. [103] succeeded in finding out the detailed reaction pathway, involving pyruvate decarboxylase [104]. Not only benzaldehyde can be subjected to baker's yeast mediated acyloin condensations. Fuganti et al. [105,106] also investigated the conversion of $\alpha, \beta$-unsaturated aldehydes giving optically active diols and used this type of reaction for the production of the C-14 
chromanyl moiety of $\alpha$-tocopherol (vitamin E) [107]. An interesting L-threonine aldolase was isolated from Candida humicola. However, only the isolated enzyme was characterized [108].

\section{Application of yeast whole-cell biocatalysis in industry} One of the first industrial processes combining microbiological and chemical synthesis was the acyloin-type condensation [109] of benzaldehyde resulting in (1R)phenylacetylcarbinol which is subsequently converted to $(1 \mathrm{R}, 2 \mathrm{~S})$-ephedrine and $(1 \mathrm{R}, 2 \mathrm{~S})$-pseudoephedrine, respectively. For that purpose, Saccharomyces cerevisiae whole cells were used in an aqueous medium [110]. The products find application for the treatment of asthma, hay fever and as a bronchodilating agent and decongestant $[74,110]$.

In addition to this application, two more lyase-based biocatalytic approaches with whole cells were employed in industry: Candida rugosa enoyl-CoA hydratase catalyzes for example one of three biotransformation steps from butyric acid to $(R)$ - $\beta$-hydroxy-n-butyric acid $[100,111]$, namely the enantioselective introduction of a hydroxy-group at the $\beta$-position of the $\alpha, \beta$-unsaturated acid which resulted after dehydrogenation. The chiral product is produced with high optical purity (>98\% ee) and a space-time yield of $5-10 \mathrm{~g} \cdot \mathrm{L}^{-1} \cdot \mathrm{d}^{-1}$. It is used for the production of a carbapenem intermediate [74]. The same whole-cell biocatalyst is also capable of converting isobutyric acid to $(R)$ - $\beta$-hydroxy-isobutyric acid, in this case with $98 \%$ yield, $97 \%$ ee and again a space-time yield of $5-10 \mathrm{~g} \cdot \mathrm{L}^{-1} \cdot \mathrm{d}^{-1}[100,111,112]$. (R)- $\beta$-hydroxy-isobutyric acid is a chiral synthon for the synthesis of captopril, an inhibitor of angiotensin converting enzyme [74]. Secondly, suspended whole cells of Rhodotorula rubra possess an L-phenylalanine ammonia lyase which performs the selective transformation of trans-cinnamic acid and ammonia to L-phenylalanine. The reaction is performed in aqueous solution at $25^{\circ} \mathrm{C}$ and $\mathrm{pH} 10.6$ and results in $85.7 \%$ yield. The L-phenylalanine is commonly applied for the production of artificial sweeteners like aspartame and in parenteral nutrition. It can also be used for the synthesis of macrolide antibiotics such as rutamycin B $[74,99,100]$.

Most yeasts which are industrially employed for wholecell biocatalysis however are used for asymmetric reductions. Eli Lilly for example employed whole cells of Zygosaccharomyces rouxii for the enantioselective reduction of 3,4-methylenedioxy-phenylacetone to the corresponding $(S)$-alcohol. Since the substrate was toxic to the microorganism, it was provided in an adsorbed form on the resin XAD-7. This allowed elevated reaction concentrations and high levels of volumetric productivity. The process showed a space-time yield of $75 \mathrm{~g} \cdot \mathrm{L}^{-1} \cdot \mathrm{d}^{-1}$ and a high optical purity (> 99.9\% ee) [113-116]. The strain Geotrichum candidum SC5469 was described to be employed by Bristol-Myers Squibb for the stereoselective reduction of 4-chloro-3-oxo-butanoic acid methyl ester to the corresponding (S)-3-hydroxyalcohol [74]. This conversion yielded the product in $95 \%$ yield and $99 \%$ ee and thus provided a useful chiral building block, e.g. for the synthesis of a cholesterol antagonist that inhibits hydroxymethyl glutaryl CoA reductase $[117,118]$. Furthermore, a second Candida sp., namely Candida sorbophila, was employed for the production of a chiral $(R)$-amino alcohol (Entry 3 in Table 2 and Additional File 2) with high optical purity (> 98\% ee; $99.8 \%$ after purification) and high chemical purity (95\%) [119]. The resulting $(R)$-amino alcohol is an important chiral synthon for the synthesis of a $\beta-3$ agonist which can be used for obesity therapy and the treatment of associated type II diabetes, coronary artery disease and hypertension [74,120].

The yeast Pichia methanolica was applied by Bristol-Myers Squibb because of its beneficial reductase for the reduction of ethyl 5-oxo-hexanoate and 5-oxo-hexanenitrile to the corresponding $(S)$-alcohols. The reaction resulted in high yield (90-95\%) and high enantiomeric excess (> 95\%) [121].

Chiral intermediates for the production of the antihypertensive drug, Omapatrilat, were produced by two different biocatalytic approaches (Entry 5 in Table 2 and Additional File 2 ): In both cases the enzyme phenylalanine dehydrogenase from Thermoactinomyces intermedius (TiPheDH) was employed for the reductive amination step and a yeast formate dehydrogenase (FDH) was required for NADH regeneration. For the first, heat-dried cells of recombinant $E$. coli with cloned TiPheDH were used together with heat-dried Candida boidinii cells, as a source of FDH. The conversion resulted in $96 \%$ yield and $>99 \%$ ee. Secondly, dried recombinant Pichia pastoris cells containing endogenous FDH and overexpressing TiPheDH were employed. The application of the second biocatalyst resulted in slightly improved yield (97.5\%) and also high enantiomeric excess (> 99\%) for the production of $(S)$-2-amino-5(1,3-dioxolan-2-yl)-pentanoic acid [122]. Regarding cofactor regeneration, $\mathrm{NAD}^{+}$produced during the reaction was in both cases regenerated to NADH by the oxidation of the auxiliary substrate formate to $\mathrm{CO}_{2}$ [123].

A resolution technique is the basis for the wholecell biocatalytic application of Trigonopsis variabilis ATCC 10679 cells. ( $\mathrm{rac}$ )-6-Hydroxynorleucine, which results after hydrolysis of commercially available 
5-(4-hydroxybutyl)-hydantoin, is converted to the ketoacid leaving the L-enantiomer. This is then isolated by ion exchange chromatography and can be used as chiral synthon, again, for the synthesis of Omapatrilat [43], the production of a vasopeptidase inhibitor, and the synthesis of C-7 substituted azepinones which represent potential intermediates for other antihypertensive metalloproteinase inhibitors [74]. The remaining 2keto-6-hydroxyhexanoic acid was further converted to L-6-hydroxynorleucine by reductive amination catalyzed by beef liver glutamate dehydrogenase ( $89-92 \%$ yield, > $99 \%$ ee, 3 h) [124]. Bacillus megaterium glucose dehydrogenase was used for $\mathrm{NAD}^{+}$recycling.

Furthermore, Saccharomyces cerevisiae was industrially employed because of its ene-reductase which belongs to the old yellow enzyme family. The substrate oxoisophorone was subjected to fermentative reduction with baker's yeast in an aqueous solution of saccharose. Periodically, substrate and saccharose were added in order to avoid toxic levels of oxoisophorone. The product 2,2,6-trimethylcyclohexane-1,4-dione resulted in $80 \%$ yield and $<97 \%$ ee and was used as intermediate for the synthesis of natural 3-hydroxycarotenoids such as zeaxanthin, cryptoxanthin and other structurally related compounds. The space-time yield of the process was given with $2.8 \mathrm{~g} \cdot \mathrm{L}^{-1} \cdot \mathrm{d}^{-1}[73,74]$.

Finally, a hydrolase-based reaction employing whole cells of Cryptococcus laurentii was used by the Japanese company Toray Industries Inc. for the synthesis of L-lysine $[99,100,125]$. For that purpose actually a combination of cells from Cryptococcus laurentii with intrinsic L-lysine lactamase and the bacterium Achromobacter obae with a lactame racemase were used. L-Lysine resulted with $>99.5 \%$ ee and was applied as nutrient and food supplement. Alternatively, the combination of cells from the yeast Candida humicola and the bacterium Alcaligenes faecalis were used. However, this process was totally replaced by highly efficient fermentation methods [74]. All above described industrial applications of yeast whole-cell biocatalysts are depicted in Table 2 and Additional File 2.

\section{Recombinant Yeasts for Whole-Cell Biocatalysis}

Remarkable progress in the field of genetic engineering made a variety of yeast strains, in particular Saccharomyces cerevisiae, susceptible to modifications by recombinant DNA technology. In the mid-1980s, a number of expression systems based on alternative yeasts appeared which eliminated some initial limitations to $S$. cerevisiae such as low yields or a high extent of undesirable hyperglycosylation. Advantages and disadvantages of such 'nonconventional' yeasts for recombinant protein production were reviewed in detail elsewhere [126-130]. Prominent established examples are Hansenula polymorpha [131], Pichia pastoris [132-134], Kluyveromyces lactis [135], Yarrowia lipolytica [136], Candida boidinii [128], and Schizosaccharomyces pombe [137], among others.

In order to circumvent disadvantages of wild-type wholecell biocatalysts, different groups started to construct 'designer yeasts' to improve first of all single-step biocatalytic syntheses. Methods for gene knockout and overexpression of heterologous enzymes, offered alternative approaches to classical techniques aiming at improving the whole-cell biocatalyst's selectivity (see Section 2). Catalytic activities of competing host-own enzymes were eliminated and desired catalytic properties could be reinforced, respectively. First, simple 'single mutants' - with one deleted or overexpressed gene were thoroughly studied but soon combinatorial approaches enlarged the spectrum of valuable wholecell biocatalysts. Of course, the identification of complete genome sequences facilitated investigations and elucidated the wealth of the host-own enzyme spectrum. Since the publication of the complete genome sequence of $S$. cerevisiae in 1996 [48,49], more than 30 yeast genomes have been completely or partly sequenced and deposited in public databases (e.g. NCBI: http://www. ncbi.nlm.nih.gov/sites/entrez?db=genome). This information is now available and ready to be exploited for the construction of valuable whole-cell factories for i.a. biocatalytic applications.

At the same time, a second branch of science, namely 'metabolic engineering', emerged in the field of genetic engineering and in 1991, Bailey [138] extensively reviewed this new field for the first time. In the following years, metabolic engineering has developed rapidly and consequently resulted in various reviews [139-142] and textbooks $[143,144]$ explaining basic principles and methodologies. The many existing examples of metabolic engineering were classified in several categories which include heterologous protein production, extension of substrate range, pathways leading to new products, pathways for the degeneration of xenobiotics, engineering of cellular physiology for process improvement, elimination/reduction of by-product formation and improvement of yield or productivity [142]. All approaches have two important parts in common: first, the identification of the most promising target(s) for genetic manipulation by solid strain analysis and second, the construction of genetically modified cells [141]. As several categories of metabolic engineering and the construction of recombinant strains for whole-cell biocatalysis target at improving similar characteristics of a cell, it is not always possible to draw a clear line between these two disciplines. However, the variety of 
recent reports on metabolic engineering of yeasts for the efficient production of top value added chemicals (e.g. ethanol, glycerol, xylitol, succinic acid and other organic acids) [145] would go beyond the scope of this review. Therefore, we refer to existing comprehensive overviews in this field of research [141,142,146-150].

In the following we focus on engineered yeast platform strains for the production of mostly chiral precursors for the pharmaceutical, food or feed industry, thereby including single- and multi-step biocatalytic reactions. Finally, we highlight recent pathway engineering efforts leading to structurally complex natural products, a field which indicates the possible catalytic scope of engineered yeasts.

\section{I Organic single or few-step transformations catalyzed by engineered yeast cells}

Employing non-engineered yeast strains for whole-cell biotransformations has often resulted in low chemical and optical purities. As selective reduction and oxidation reactions are the most thoroughly investigated applications of whole-cell yeast biocatalysts, the first recombinant yeast strains were also engineered for this class of biotransformations. Several groups subjected $S$. cerevisiae to step-by-step gene knockout and overexpression of various reductases and studied the catalytic properties of the resulting engineered yeast strains in detail (Table 3 and Additional File 3).

In 1985, Shieh et al. [151] already succeeded in improving the optical purity for ethyl (R)-4-chloro-3hydroxybutanoate production starting with the prochiral $\beta$-keto ester. They employed the S. cerevisiae ATCC 26403 mutant lacking a competing $\beta$-keto reductase and achieved $90 \%$ ee compared to $57 \%$ ee for the wild-type strain [151]. Fifteen years later, Rodríguez et al. [152] altered the levels of three S. cerevisiae oxidoreductases, namely fatty acid synthase (Fasp), aldo-keto reductase (Ypr1p), and $\alpha$-acetoxy ketone reductase (Gre2p), respectively. They first created a set of 'first-generation' yeast strains deleting or overexpressing only one single enzyme at a time. Based on subsequent results, a 'second-generation' set of yeast strains was constructed, combining gene deletion and overexpression. Several $\beta$-keto esters were used as substrates and among the engineered strains not only significantly improved stereoselectivities compared to the wild-type but also engineered strains with inverted selectivities were found [152] (see for example Table 3 and Additional File 3, Entry 2, Substrate d and e). However, this study also revealed that additional yeast proteins exist which might participate in the reduction of some of the subjected $\beta$-keto ester substrates and deteriorate especially enantiopurities. Later, forty-nine open reading frames encoding for potential reductase activities were elucidated in the complete $S$. cerevisiae genome [68]. However, up to now not all corresponding reductases have been investigated in detail. Some selective alternative $S$. cerevisiae reductases were identified and examined by Gorwa-Grauslund and coworkers $[153,154]$. Overexpressing the NADPH-dependent reductases Ara1p, Ypr1p and YMR226c, respectively, led to yeast strains with increased yield $(\geq 48 \%)$ and enantiomeric excess $(\geq 87 \%)$ for the conversion of diacetyl to $(S)$-acetoin (wild-type: $42 \%$ yield, $80 \%$ ee) $[153,154]$. Furthermore, Johanson et al. [155] improved the asymmetric reduction of a bicyclic diketone to $(1 R, 4 S, 6 S)$-6-hydroxy-bicyclo[2.2.2] octane-2-one which is used as intermediate for the production of transition metal-based chiral chemical catalysts [156]. A combination of reaction and strain engineering (overexpression of the S. cerevisiae reductase YDR368w in S. cerevisiae Table 3 and Additional File 3 ) led to $84 \%$ yield, > 99\% ee and $97 \%$ de compared to initially described results with $52 \%$ yield, $95 \%$ ee, and $84 \%$ de - after chromatography and crystallization [157]. Recently, Kratzer et al. [158] succeeded in overcoming limitations of baker's yeast in the asymmetric reduction of $\alpha$-keto esters using also a combinatorial approach. They improved the enzyme by exchanging the amino acid residue tryptophane 23 with phenylalanine (CtXR-W23F) which resulted in an up to eightfold higher NADH-dependent activity compared to the wild-type enzyme employing a series of aromatic $\alpha$-keto esters as substrates [159]. The strain $S$. cerevisiae was engineered to efficiently overexpress CtXR-W23F by introducing multiple copies of the expression cassette (strain S.c. WF2 $\mu$ ). Finally, the reaction itself was optimized performing it under anaerobic conditions in the presence of EtOH. Thereby NADH-regeneration was preferred. This was accomplished by the yeast's own NADH-dependent alcohol dehydrogenase $(\mathrm{ADH})$ and $\mathrm{NAD}(\mathrm{P}) \mathrm{H}$-dependent aldehyde dehydrogenase (AlDH). Thus, the action of endogenous NADPH-dependent yeast reductases with diverse enantiopreferences was suppressed [158]. $\alpha$-Hydroxy esters were obtained in acceptable yields and high enantiopurities ( $\geq 99.4 \%$ ee, see Table 3 and Additional File 3, Entry 6).

Exploiting the advantage of S. cerevisiae to be 'Generally Regarded As Safe' (GRAS) for human consumption, Farhi et al. [160] engineered this yeast for the improved synthesis of the food flavoring methyl benzoate. This was achieved by expressing the Antirrhinum majus benzoic acid methyltransferase (BAMT) under the control of the copper-inducible CUP1 promoter. A yield of $\sim 1 \mathrm{mg}$ methyl benzoate per liter of culture was achieved after $24 \mathrm{~h}$, starting with benzoic acid. In addition, it was 


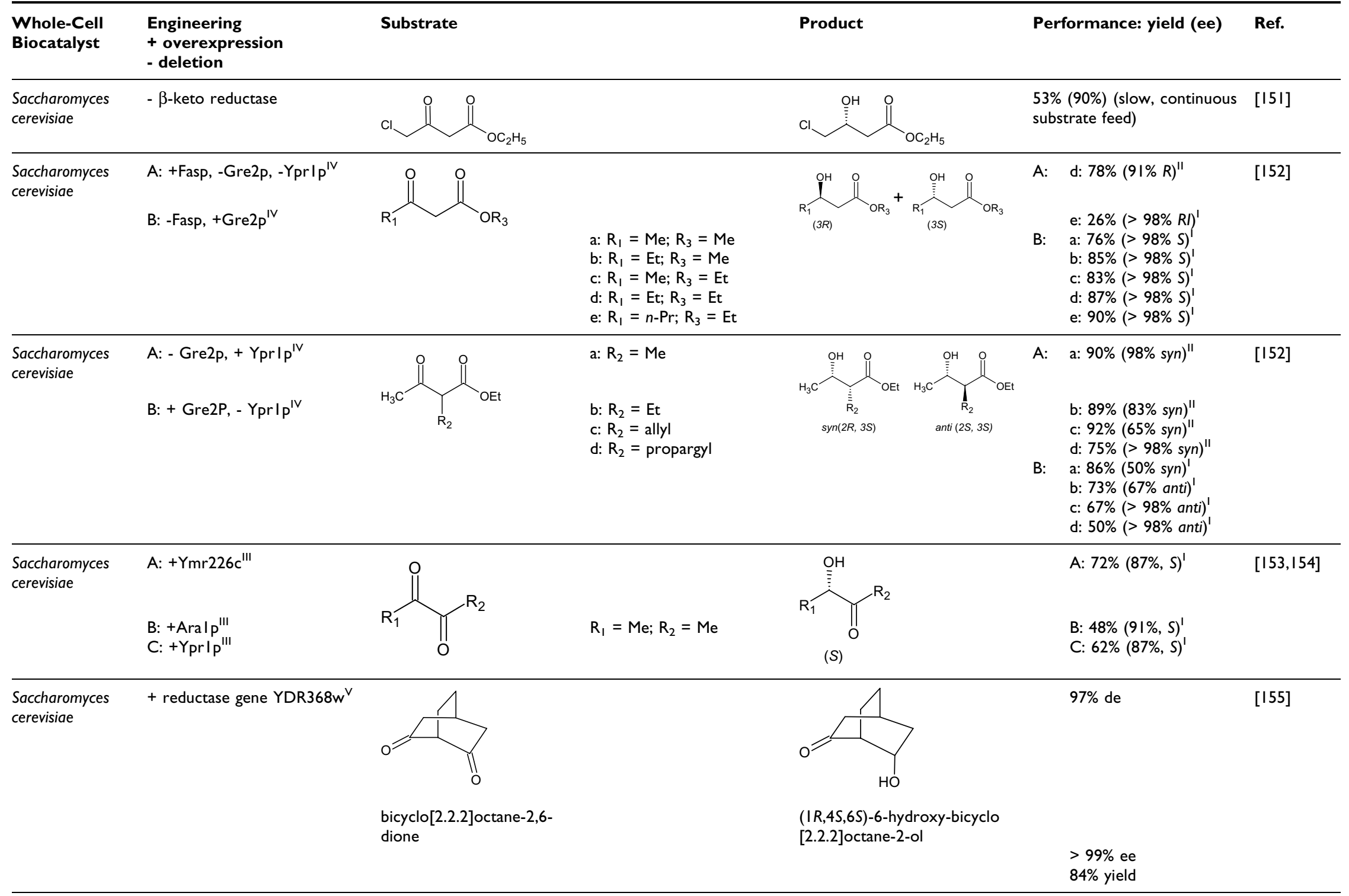




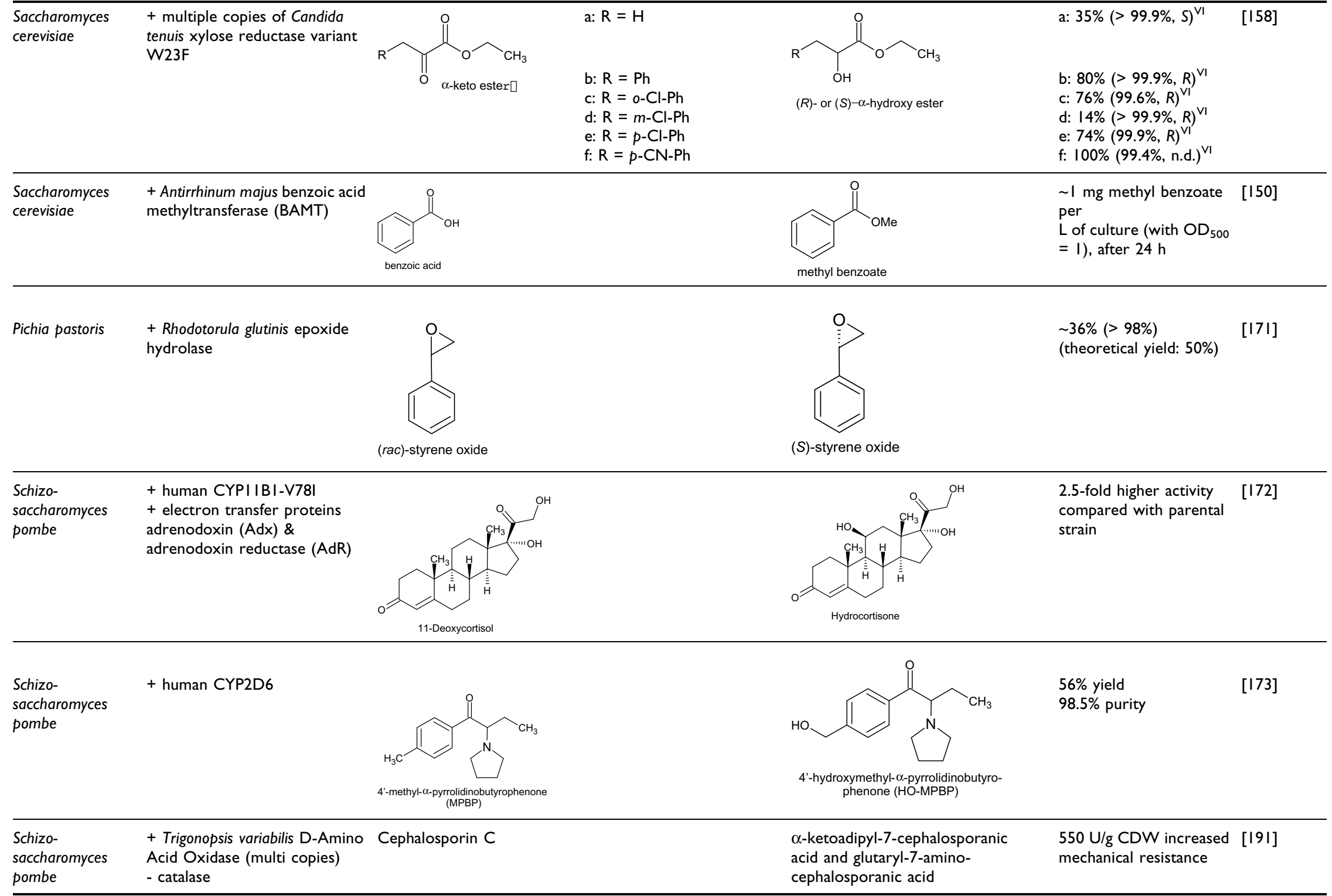

'carbon source: glucose; "carbon source: galactose; "'I Aralp = S. cerevisiae reductase, NADPH-dependent; YprIP = S. cerevisiae reductase, NADPH-dependent; YMR226c = S. cerevisiae shor chain dehydrogenase ORF [153]; ${ }^{\prime \vee}$ Fasp $=S$. cerevisiae fatty acid synthase; $G r e 2 p=S$. cerevisiae $\alpha$-acetoxy ketone reductase; $Y p r I p=S$. cerevisiae aldo-keto reductase [152]; ${ }^{\vee} S$. cerevisiae 2-methylbutyraldehyde reductase (NCBI accession number: NP 0I 0656); ${ }^{\mathrm{V}}$ Whole-cell bioreductions of $\alpha$-keto esters (I0 mM) under anaerobic conditions using I M ethanol as co-substrate; n.d. $=$ not determined. 
demonstrated that yeast strains expressing BAMT were more tolerant towards benzoic acid. Several groups also focused on engineering $S$. cerevisiae in order to modulate and improve the formation of antioxidants and aroma compounds during wine fermentation. In 2000, González-Candelas et al. [161] used a transgenic yeast strain for the improved production of resveratrol, an antioxidant which was reported to possess cancer chemoprotective properties [162,163]. They expressed the Candida molischiana bglN gene encoding for a $\beta$-glucosidase in the industrial wine yeast $S$. cerevisiae T73 (CECT1894) and yielded elevated contents of both trans- and cisresveratrol $(\geq 0.75 \mu \mathrm{M})$ compared to the wild-type $(\geq 0.25 \mu \mathrm{M})$ [161]. Further engineering concepts for improved resveratrol production with recombinant yeast strains are discussed in detail in chapter 3.4. Subsequently, Genovés et al. [164] optimized the production of recombinant Candida molischiana BGLN enzyme in $S$. cerevisiae and tested the purified BGLN enzyme for vinification experiments. The efficient release of terpenes and alcohols from Muscat wine glycosides was observed. Smit et al. [165] tried to develop wine yeasts with optimized decarboxylating activity on phenolic acids. Therefore, two different phenolic acid decarboxylases (PADC from Bacillus subtilis and p-coumaric acid decarboxylase (PDC) from Lactobacillus plantarum) were expressed in S. cerevisiae under the control of the constitutive $S$. cerevisiae phosphoglyceratekinase I gene promoter and terminator $\left(\mathrm{PGK} 1_{\mathrm{P}}\right.$ and $\left.\mathrm{PGK} 1_{\mathrm{T}}\right)$. In most of the Chardonnay and Riesling wines, the vinification done by the recombinant strains resulted in slightly increased 4-ethylphenol, 4-vinylphenol and 4-vinylguaiacol concentrations. However, first results of industrial yeast fermentation analysis showed very high concentrations of volatile phenols close to and even higher than the ideal concentration. Thus, further improvements are necessary including a better regulation of the recombinant enzyme's overproduction or the preevaluation of the available concentration of precursor namely phenolic acid components - in the grape juice. Cordente et al. [166] engineered S. cerevisiae in order to optimize concentrations of volatile esters which represent the largest and most important group of wine flavoring components produced during fermentation. They overexpressed the major mitochondrial and peroxisomal carnitine acetyltransferase (CAT2p) from $S$. cerevisiae but instead of increased levels of ester compounds reduced concentrations were observed. The authors hypothesized that the overexpression of Cat2p favors the production of acetylcarnitine and CoA and therefore limits the precursor for ester formation [166].

Finally, Stewart and coworkers tested a Saccharomyces cerevisiae strain expressing the cyclohexanone monooxygenase from the bacterium Acinetobacter sp. NCIB 9871 with a variety of substituted cycloalkanones [167-170] and several sulfides, dithianes and dithiolanes [88], respectively (Table 4 and Additional File 4). Thereby, they combined the broad substrate tolerance of the enzyme with baker's yeast tolerance for relatively high concentrations of organic compounds, providing a stable environment for the enzyme. Furthermore, no enzyme purification or additional NADPH-regeneration system was necessary and the enzyme from this potentially pathogenic bacterial strain (class II) [88] became easily accessible. Enzyme induction in the Acinetobacter strain also required the addition of cyclohexanol which complicated product isolation [68]. Table 4 and Additional File 4 depicts detailed results of enantioselective Baeyer-Villiger oxidations with the above described 'designer yeast'. Although high optical purities were achieved with the majority of investigated substrates, it is still clear that yields must be improved significantly in order to allow the biocatalyst's commercial application [68].

In addition to $S$. cerevisiae strains, also alternative yeasts were genetically modified to exhibit beneficial oxidoreductase properties (Table 3 and Additional File 3). Rhodotorula glutinis epoxide hydrolase was for example overexpressed in Pichia pastoris leading to a 10-fold elevated activity toward $(R)$-styrene oxide conversion compared to the R. glutinis wild type. Kinetic resolution of racemic styrene oxide yielded in the $(S)$-styrene oxide with $98 \%$ ee and $36 \%$ yield [171]. A recombinant Schizosaccharomyces pombe strain coexpressing the human cytochrome P450 CYP11B1 mutant V78I and the electron transfer proteins adrenodoxin (Adx) and adrenodoxin reductase (AdR) showed a 2.5-fold higher $11 \beta$ hydroxylation activity than the parental strain for the production of hydrocortisone [172]. Furthermore, Peters et al. [173] developed a Schizosaccharomyces pombe strain expressing human CYP2D6 and evaluated its principle feasibility for the synthesis of $4^{\prime}$-hydroxymethyl- $\alpha$ pyrrolidinobutyrophenone (56\% yield, $98.5 \%$ purity Table 3 and Additional File 3). Other yeast whole-cell biocatalysts which were engineered to display enzymes on their surface are described in section 3.3.

\subsection{Cofactor regeneration using genetically engineered yeasts}

As far as organic biotransformations are concerned, the most common application of yeast whole-cell biocatalysts is for asymmetric reductions. For these synthetically useful reactions cofactor-dependent enzymes are required. Considering the cost of $\mathrm{NAD}(\mathrm{P})^{+}$and $\mathrm{NAD}$ (P) $\mathrm{H}$, their stoichiometric application is not economically feasible unless an efficient regeneration method is employed which allows the use of only low amounts [174]. In general, whole-cell biocatalysts provide the cheapest cofactor regeneration system preventing the 
Table 4: Examples for one step enzymatic reactions employing the designer yeast made by Stewart and coworkers [88, 167-I70] namely Saccharomyces cerevisiae overexpressing the Acinetobacter sp. NCIB 987 I cyclohexanone monooxygenase. The data is chronologically ordered

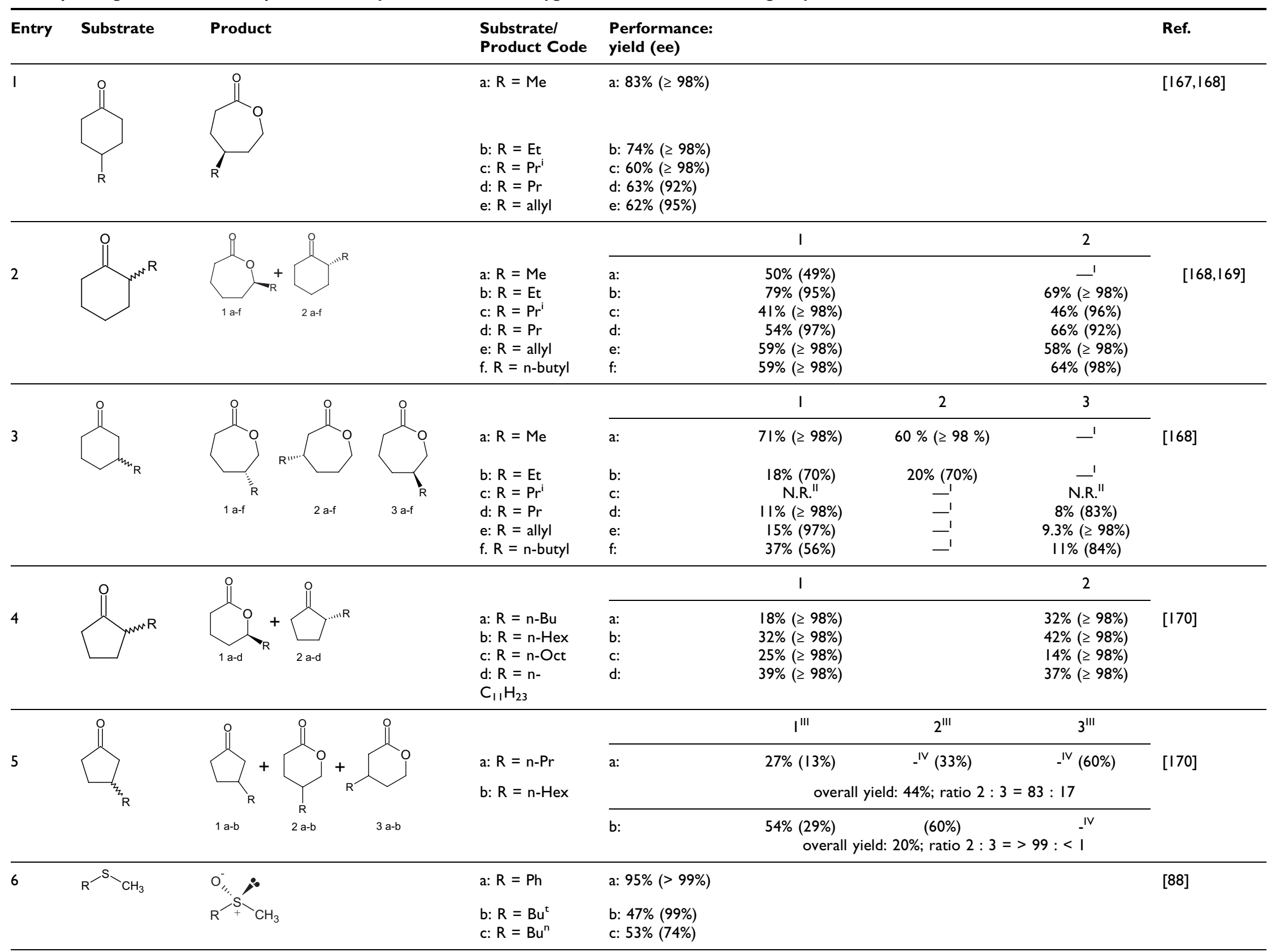


Table 4: Examples for one step enzymatic reactions employing the designer yeast made by Stewart and coworkers [88, 167-170] namely Saccharomyces cerevisiae overexpressing the Acinetobacter sp. NCIB 987I cyclohexanone monooxygenase. The data is chronologically ordered (Continued)

[88]
[8:

'This isomer was not detected in the product mixture [168];

"no oxidation detectable [168];

"II due to the low enantioselectivities of the reactions, no absolute configuration was assigned [170];

value not given [170]. 
laborious procedure of enzyme isolation and taking advantage of prolonged enzyme stability and cofactor recycling from cheap auxiliary substrates. However, there exist several disadvantages when employing wild-type whole-cell biocatalysts (see Section 1.1).

Recently, improvements in cofactor regeneration systems were comprehensively reviewed focusing on pyridine nucleotide regeneration [175], cofactor regeneration with genetically engineered bacteria [176] and new methods for the improved regeneration of ATP/NTP, sugar nucleotides and PAPS (3'-phosphoadenosine-5'-phosphosulfate) which is involved in sulfuryl transfer reactions [177]. In most cases however isolated enzymes and genetically modified bacteria were employed. Regarding again $S$. cerevisiae, only traditional approaches were followed, using the yeast for its supply of reducing power and encountering serious drawbacks when trying to freely combine it with desired non-natural substrates. Stewart and coworkers $[47,68,168]$ were among the first scientists who constructed genetically engineered $S$. cerevisiae strains and thereby reduced undesirable dehydrogenase background reactions by deleting single reductase genes. Thus, it became again more attractive to utilize the $S$. cerevisiaeown cofactor regeneration system for the asymmetric reduction of selected ketones. However, considering all attempts it seems that the potential of $S$. cerevisiae as whole-cell redox-biocatalyst has not been fully exploited yet. The huge number of existing $S$. cerevisiae genes encoding for reductases suggests a more complex strategy such as temporarily silencing of metabolic pathways either by reaction engineering as indicated by Kratzer et al. [158] (see Chapter 3.1, Table 3 and Additional File 3) or by regulation of gene expression, a perhaps more challenging approach.

At the same time, metabolic engineers also investigated the impact of cofactor engineering on the redox metabolism of S. cerevisiae. Nissen et al. [178] expressed for example the cytoplasmic transhydrogenase from Azotobacter vinelandii in S. cerevisiae CBS8066. Transhydrogenases, which were not found in yeasts $[179,180]$, catalyze the hydrogen transfer between the two cofactor systems $\mathrm{NADH} / \mathrm{NAD}^{+}$and $\mathrm{NADPH} / \mathrm{NADP}^{+}$. Nissen's results indicated that when introducing a transhydrogenase in yeast, the conversion of NADP(H) and $\mathrm{NAD}^{+}$to $\mathrm{NADP}^{+}$and NADH was favored [178]. This was already observed by Anderlund et al. [181] who constructed recombinant $S$. cerevisiae strains expressing a membrane-bound E. coli transhydrogenase. In contrast, Nielsen and coworkers [182] also succeeded in constructing genetically engineered $S$. cerevisiae strains with a modified ammonium assimilation pathway for increased NADPH availability. Therefore, the NADPH-consuming glutamate dehydrogenase (GDH1) was deleted and an alternative pathway consisting of an NADH-consuming
GDH2 or the ATP-dependent glutamine synthetase (GLN1) and the NADH-dependent glutamate synthase (GLT1) was introduced. The major redox alteration of the engineered strain was shown by a reduced flux through the pentose phosphate pathway during aerobic growth on glucose. Finally, this switch in cofactor requirement for ammonia assimilation resulted in both an increase in ethanol yield $(10 \%)$ and a significant reduction of the glycerol yield ( $40 \%)$ [183]. Furthermore, S. cerevisiae strains with a decreased intracellular NADH pool were generated by expressing the Lactobacillus lactis $\mathrm{H}_{2} \mathrm{O}$-forming NADH oxidase [184]. A major consequence of the thus provided $\mathrm{NAD}^{+}$excess led to a significant reduction in ethanol yield (15\%). This strategy could provide a route to reduce and adjust the ethanol content of fermented beverages like beer or wine [184]. The overexpression of alternative oxidases could also result in valuable strains for $\mathrm{NAD}^{+}$regeneration.

Recently, the methylotrophic yeast Pichia pastoris was engineered for efficient NADH regeneration in our laboratory (F. S. Hartner, personal communication). The concept included the decrease in $\mathrm{MeOH}$ assimilation by deleting two dihydroxyacetone synthase genes. Thereby, the existing methanol utilization pathway generating two molecules of $\mathrm{NADH}$ while methanol is irreversibly oxidized to $\mathrm{CO}_{2}$ - was enhanced. This approach led to improved space-time yields and specific conversion rates for the conversion of acetoin to 2,3butanediol catalyzed by the overexpressed $S$. cerevisiae butanediol dehydrogenase. In this case, methanol was used as a cosubstrate for NADH regeneration but also as an inducer for the expression of the heterologous catalyst and the endogenous NADH regeneration pathway.

Furthermore, engineered S. cerevisiae cells overexpressing hexokinase or glucokinase were reported to almost completely convert adenosine (130 mM) to ATP [185], providing a possible ATP regeneration system [25].

Again E. coli and the yeast S. cerevisiae are the most often and thoroughly studied organisms regarding attempts to optimize cofactor recycling by genetic engineering. However, especially methylotrophic yeasts provide interesting alternatives for engineering endogenous cofactor recycling pathways.

\subsection{Transport limitations and displaying enzymes}

on the surface of yeast whole-cell biocatalysts

Considering whole-cell processes, it would be ideal if the starting material was transported into the cell and if products were released without any limitation. The production rate would then only be dependent on the cell's metabolic functions including the catalyst's kinetic 
limitations. In reality, bioprocesses are often drastically limited by barrier functions of the cell wall or membrane. In order to circumvent these limits, permeabilization methods are common practice. Recently, Chen [186] reviewed standard permeabilization protocols including efficient methods for yeasts such as solvent [187-189], detergent [190] or alkaline [191] treatment and air-drying at $42^{\circ} \mathrm{C}$ [192], respectively. However, classical permeabilization methods often show serious shortcomings causing extensive damage to membrane systems, even cell lysis [193], which makes cofactor regeneration or the reuse of the catalyst impossible. Furthermore, downstream processing can be complicated. Recently, molecular engineering approaches provided an alternative route to solve the cell permeability issue in a way that can be better predicted [186]. Either outer membrane structures were engineered - a method which was up to now only used for bacterial cells - or enzymes were displayed on the cell surface. In the following the later method will be discussed in more detail.

Molecular displaying techniques allow the targeting of heterologous proteins to the surface of yeast strains. They are covalently linked to the internal, skeletal layer of $\beta-1,3-$ and $\beta-1,6$ glucan complexed with chitin and protrude to the outer layer of glycoproteins [194]. This technique provides several advantages: The anchoring to the cell surface can eliminate purification and separation processes and result in increased biocatalyst stability. Benefits of $S$. cerevisiae which has GRAS status and is well suited for the expression of proteins from eukaryotes can be combined with economic aspects like facilitated biocatalyst recycling due to the self-immobilization of the recombinant enzymes, simple cultivation and fast growth to high cell densities. Furthermore, mass transport problems of substrate and/or product across the cell membrane can be prevented as the enzyme, necessary for catalysis, is displayed on the cells' surface $[195,196]$. This is especially important when polymeric compounds are used as substrates. In spite of these benefits, current disadvantages of whole-cell biocatalysts with enzymes anchored to their cell wall should not be neglected such as current limitations to one- or few-step reactions, the restriction to simple biotransformations independent of costly cofactors and the loss of the protective subcellular environment providing optimal ionic, $\mathrm{pH}$ - and redox-conditions for enzymatic reactions. However, one or the other disadvantage could be solved by further genetic engineering approaches such as co-displaying of a cofactor-dependent oxidoreductase and an enzyme for cofactor recycling or the engineering of the outer membrane structure of yeast cells to improve the conditions in the vicinity of the displayed enzyme.

In particular, Japanese scientists succeeded in developing the first enzyme-displaying yeast cells and investigated their application for whole-cell biocatalysis focusing on hydrolases. They studied for example the optical resolution of $(R S)$-1-phenylethanol by enantioselective transesterification with vinyl acetate [197]. Therefore, S. cerevisiae MT8-1 cells were employed which displayed the pro-region of Rhizopus oryzae lipase (ProROL) by fusing the flocculation functional region of the cell-wall protein Flo1p to the lipase's N-terminus [198]. The conversion resulted in the $(R)$-1-phenylethyl acetate with high yields and enantiomeric excess (> 93\%) [197]. Furthermore, Kondo and coworkers [199] applied S. cerevisiae cells displaying Rhizopus oryzae lipase (ROL) for the optical resolution of $(R, S)$-1-benzyloxy-3-chloro-2-propyl monosuccinate. After a reaction time of $16 \mathrm{~h}$, the ROL-displaying yeast had hydrolyzed the $(R)$-compound with an $e_{\mathrm{p}}$-value of $95.5 \%$ and a conversion of $50.2 \%$, whereas the employment of soluble $R$. oryzae lipase (F-AP15, Amano enzyme Inc., Japan) showed quite poor ee and conversion $\left(58.7 \% \mathrm{ee}_{\mathrm{p}}\right.$ $35.9 \%$ conv., at $12 \mathrm{~h}$ ) [199]. The stability of ROLdisplaying yeast cells was confirmed by reusing the biocatalyst eight times without significant activity loss. The displaying-technique was also combined with enzyme engineering: Shibamoto et al. [200] constructed a surfacedisplayed combinatorial library of $R$. oryzae lipase in $S$. cerevisiae which resulted in new biocatalysts with increased activity for the hydrolysis and methanolysis, respectively, of soybean oil. Methanolysis yields in methyl esters constituting a potential biodiesel fuel. Recently, Kaya et al. [201] reported the production of isoflavone aglycones from isoflavone glycosides employing $S$. cerevisiae cells. Three different $\beta$-glucosidases from Aspergillus oryzae were individually displayed on the yeast cell surface. The engineered yeast strain with the $\beta$-glucosidase BGL1 (gene ID: AO090003001511 from the A. oryzae RIB40 genome) exhibited the highest $\beta$-glucosidase activity and first wholecell biotransformations were performed to produce the isoflavone aglycones daidzein, glycitein and genistein. Furthermore, Kim et al. [202] described the production of cyclofructans from inulin. They engineered S. cerevisiae to display cycloinulooligosaccharide fructanotransferase from Paenibacillus macerans on the cell surface. As major product, cycloinulohexaose was detected along with cycloinuloheptaose and cycloinulooctaose as minor products. Yeast surface display was also used by Wittrup and coworkers for the FACS-based selection of horseradish peroxidase variants with enhanced enantioselectivity toward L- and D-tyrosinol, respectively [203].

Another lipase was displayed by Ueda and coworkers [204]. They developed S. cerevisiae cells displaying a mutated form of Candida antarctica lipase B which was constructed on the basis of the primary sequences of the CALBs from C. antarctica CBS 6678 and C. antarctica LF 058 , respectively. $\alpha$-Agglutinin was used as anchor protein. The newly generated biocatalyst displayed high thermal 
stability $\left(T_{1 / 2}\left(60^{\circ} \mathrm{C}\right)=30 \mathrm{~min}\right)$ and $>6$-fold higher activity for the hydrolysis of p-nitrophenyl butyrate compared to previously reported CALB mutants generated by Zhang et al. (CALB-23G5: $86 \mathrm{nmol} / \mathrm{min} / \mu$ g protein) [205]. However, despite of several advantages such as for example straight-forward library construction and screening, whole cells displaying enzymes still possess their own pool of wild-type enzymes that might act on provided substrates able to diffuse through the cell membrane. Considering especially esterolytic and lipolytic activities which are quite common in all organisms, this might lead to undesirable by-products and a significant reduction of chemical and optical yield.

A great benefit of the enzyme displaying technique is the prevention of mass transport problems of the substrate across the cell membrane. This makes polymeric compounds amenable as substrates for whole-cell biocatalysis. In the following some examples are given describing the successful degradation of different polymeric substrates by recombinant $S$. cerevisiae cells displaying enzymes on their cell surface. More details were summarized by Ueda and Tanaka [206] and Wu et al. [207], respectively. Fukuda et al. [196] produced chitooligosaccharides from a chitosan polymer employing yeast cells with Paenibacillus fukuinensis chitosanase on the yeast surface. The products are a remarkable resource for the development of e.g. functional food and diverse materials such as artificial skin [196]. Fujita et al. [208] constructed a Saccharomyces cerevisiae whole-cell biocatalyst displaying Trichoderma reesei xylanase II for the degradation of xylan. Furthermore, they developed a yeast strain (S. cerevisiae) which co-displayed three types of cellulolytic enzymes: Trichoderma reesei endoglucanase II, T. reesei cellobiohydrolase II and Aspergillus aculeatus $\beta$-glucosidase 1 [209]. The generated whole-cell biocatalyst performed the saccharification and subsequent fermentation of amorphous cellulose and produced $0.45 \mathrm{~g}$ ethanol per gram of carbohydrate consumed (88.5\% yield).

Although the cell wall of Saccharomyces cerevisiae is the one which is the best characterized among yeasts $[210,211]$, targeting proteins is also applicable to alternative variants. Kluyveromyces lactis, for example, was used to test this and cell-associated $\alpha$-galactosidase activity was detected [194]. Recently, Jiang et al. [212] reported for the first time the displaying of an enzyme on Pichia pastoris KM71, namely the lipase LipB52 from Pseudomonas fluorescens B52. Engineered P. pastoris strains featured a slightly improved thermal stability compared to a Saccharomyces cerevisiae EBY100-pLHJ026 strain displaying the same lipase. Furthermore, Yue et al. [213] developed a new plasmid for the display of proteins on Yarrowia lipolytica cells providing the basis for applications in the field of whole-cell biocatalysis.

\subsection{Synthetic pathways in yeasts}

The construction and employment of 'designed strains' for natural product biosynthesis clearly indicate the potential of yeast engineering. In recent years, remarkable progress paved the way for the design of whole-cell biocatalysts capable of producing structurally complex natural products and novel variations thereof. An exponentially increasing number of sequences was elucidated. New bioinformatic tools providing the basis for analyzing this load of information were developed and sophisticated tools for engineering heterologous hosts were established.

Natural products like isoprenoids, flavonoids or polyketides represent structurally complex compounds which are often routinely made in nature but require long and elaborate synthesis routes when classical chemical methods are employed. Compounds of all three classes have attracted attention because of their great commercial potential. The class of isoprenoids includes for example carotenoids which are valuable antioxidants and food and feed additives, steroids which are widely used as drugs constituting antiinflammatory, contraceptive and anticancer agents, or terpenoids like the well-known diterpenoid taxol with its excellent activity, also against a range of cancers. Flavonoids which derive from the phenylpropanoid pathway possess anti-allergenic, anti-inflammatory, and anti-oxidant activities in humans, and polyketides are applied for the treatment of cancer (adriamycin), cardiovascular diseases (lovastatin), immunosuppression (rapamycin, tacrolimus) or infectious diseases (erythromycin, tetracycline) [214].

As the structural complexity makes the chemical synthesis of natural products quite difficult, fermentation is regarded to be an economically feasible alternative to produce pharmaceutically useful compounds for commercial purposes. Most native organisms producing complex polyketide- or isoprenoid-derived compounds do not provide high-levels of these substances as they tend to grow slowly. In addition, they are often not amenable to genetic manipulation. Thus, alternative heterologous systems with faster growth and established genetic engineering techniques seem to provide an interesting alternative with respect to volumetric productivity. The relatively homogenous processes towards the final products are another great benefit of natural product pathways. Precursors and enzymes of natural product synthesis pathways are closely related and a kind of modular system can be established in order to produce different natural but also novel compounds with therapeutic properties. Improvements of manufacturing processes are thus possible at a more rapid pace. Essential for the understanding of the synthetic pathways are not only genetic techniques for their manipulation but also the molecular understanding of every individual biocatalytic step, hence the information gained by simple one-step biochemical reactions. 
So far, Saccharomyces cerevisiae represented again an ideal host for synthetic pathway engineering due to its rapid growth, advanced fermentation techniques and well established genetic tools [215]. In the following some examples are given employing $S$. cerevisiae, but also Candida utilis which was engineered for carotenoid production (Table 5: Additional File 5 and 6: Additional File 6).

Carotenoids represent one of the first classes of natural compounds produced by recombinant yeast strains. Gene clusters responsible for the synthesis of carotenoids were isolated from carotenogenic bacteria, including for example Erwinia sp. and Agrobacterium aurantiacum. Their function was elucidated [216,217], and essential genes were introduced to $S$. cerevisiae and C. utilis, respectively [218-220]. S. cerevisiae and C. utilis are capable of accumulating ergosterol as their principle isoprenoid compound. Obviously, this strongly suggested the possibility of redirecting the pathway partly to carotenoid production. Finally, engineered $C$. utilis strains $[218,219]$ surpassed recombinant $S$. cerevisiae strains [221-223] in the production of $\beta$-carotene and lycopene (Table 5 and Additional File 5). Actually, C. utilis strains performed even better than engineered E. coli, especially for lycopene production (C. utilis: up to $7.8 \mathrm{mg} / \mathrm{g}$ CDW [218]). Engineered E. coli strains were found to accumulate more than $1 \mathrm{mg} / \mathrm{g} \mathrm{CDW}$ of lycopene, $\beta$-carotene and zeaxanthin, and more than $0.5 \mathrm{mg} / \mathrm{g} \mathrm{CDW}$ of astaxanthin [220].

In general, the pivotal intermediate of all isoprenoid compounds produced in a cell is farnesyl pyrophosphate [224], which also represents the branching point of the diverse isoprenoid biosynthetic pathways (Figure 3). Eukaryotic cells possess a variety of isoprenoid compounds, which are involved in a vast array of cellular processes such as post-translational modification of proteins (prenylation) and tRNA modification. They represent compounds of the lipid bilayer, electron transporters during respiration, cofactors involved in enzyme catalysis, and hormones for signal transduction.

In 1999, Dimster-Denk et al. [225] investigated the regulation of the isoprenoid pathway in S. cerevisiae. They evaluated the expression of all genes fusing them to reporter constructs which allowed both, the profiling of gene transcription and translation. Therefore, the Acacia's yeast Genome Reporter Matrix ${ }^{\mathrm{TM}}$ (GRM) was used, consisting of reporter-gene-fusion-constructs to $>95 \%$ of all $S$. cerevisiae genes encoding proteins.

A recent highlight of synthetic pathway engineering was reported by Keasling and coworkers [226]. They engineered Saccharomyces cerevisiae for artemisinic acid (a structurally complex precursor of artemisinin) production with titers of up to $100 \mathrm{mg} / \mathrm{L}$. As natural artemisinin - extracted from the plant Artemisia annua $\mathrm{L}$ - is highly effective against parasitic Plasmodium spp., its improved production would preserve the drug's short supply and make it more affordable to most malaria sufferers. Therefore, Ro et al. [226] improved the mevalonate pathway, introduced amorphadiene synthase, and a novel cytochrome P450 monooxygenase (CYP71AV1) from A. annua that performed together with its native redox partner CPR (NADPH:cytochrome P450 oxidoreductase) from A. annua a three-step oxidation of amorpha-4,11-diene to artemisinic acid. The synthesized artemisinic acid was then transported out of the cell and was retained on the outside of the engineered yeast, constituting a simple and inexpensive purification process for product isolation. In a next step, Shiba et al. [227] enhanced the supply of acetyl-CoA to the mevalonate pathway and gained elevated levels of amorphadiene. This was achieved by engineering the pyruvate dehydrogenase bypass in $S$. cerevisiae. Overproduction of acetaldehyde dehydrogenase and introduction of a Salmonella enterica acetyl-CoA synthetase variant increased the carbon flux into the mevalonate pathway. This engineering step is generally applicable to the improvement of the production of isoprenoid compounds in yeast (see also Figure 3 and last entry in Table 5 and Additional File 5).

Furthermore, the major adrenal glucocorticoid of mammals, hydrocortisone, was artificially synthesized by recombinant Saccharomyces cerevisiae [228]. Therefore, a fully self-sufficient biosynthetic pathway involving 13 engineered genes was assembled and expressed in a single yeast strain. Endogenous sterol biosynthesis was rerouted to produce compatible sterols which served as substrates for the heterologous part of the pathway. The biosynthesis involved eight mammalian proteins and further optimization required the modulation of two mitochondrial systems and the disruption of unwanted side reactions associated with the formation of several unnecessary gene products. Jackson et al. [229] succeeded in engineering $S$. cerevisiae for the increased production of the yeast-foreign sesquiterpene epi-cedrol. Yields of up to $0.37 \mathrm{mg} / \mathrm{L}$ were obtained after introduction of the Artemisia annua epi-cedrol synthase gene, overexpression of a truncated hydroxy-methylglutaryl CoA reductase and use of a $S$. cerevisiae upc2-1 mating type a background. Finally, the first steps of the Taxol biosynthesis pathway were transferred to $S$. cerevisiae. However, DeJong et al. [230] determined only small amounts $(0.025 \mathrm{mg} / \mathrm{L})$ of taxadien- $5 \alpha$-ol but no in vivo detection of taxadien- $5 \alpha$-acetoxy- $10 \beta$-ol was possible. 




CrtB and crt

$\rightarrow$ lycopene), respectively, under the control of

Introduction of Erwinia herbicola carotenoid zeaxanthin production under the control of $S$. cerevisiae promoters and terminators [222]

Lycopene: $0.113 \mathrm{mg} / \mathrm{g}[\mathrm{CDW}]$

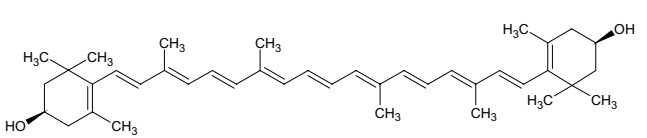

Zeaxanthin: $0.01 \%$ of CDW $\sim 0.2-0.05 \mathrm{mg} / \mathrm{g}$ [CDW]

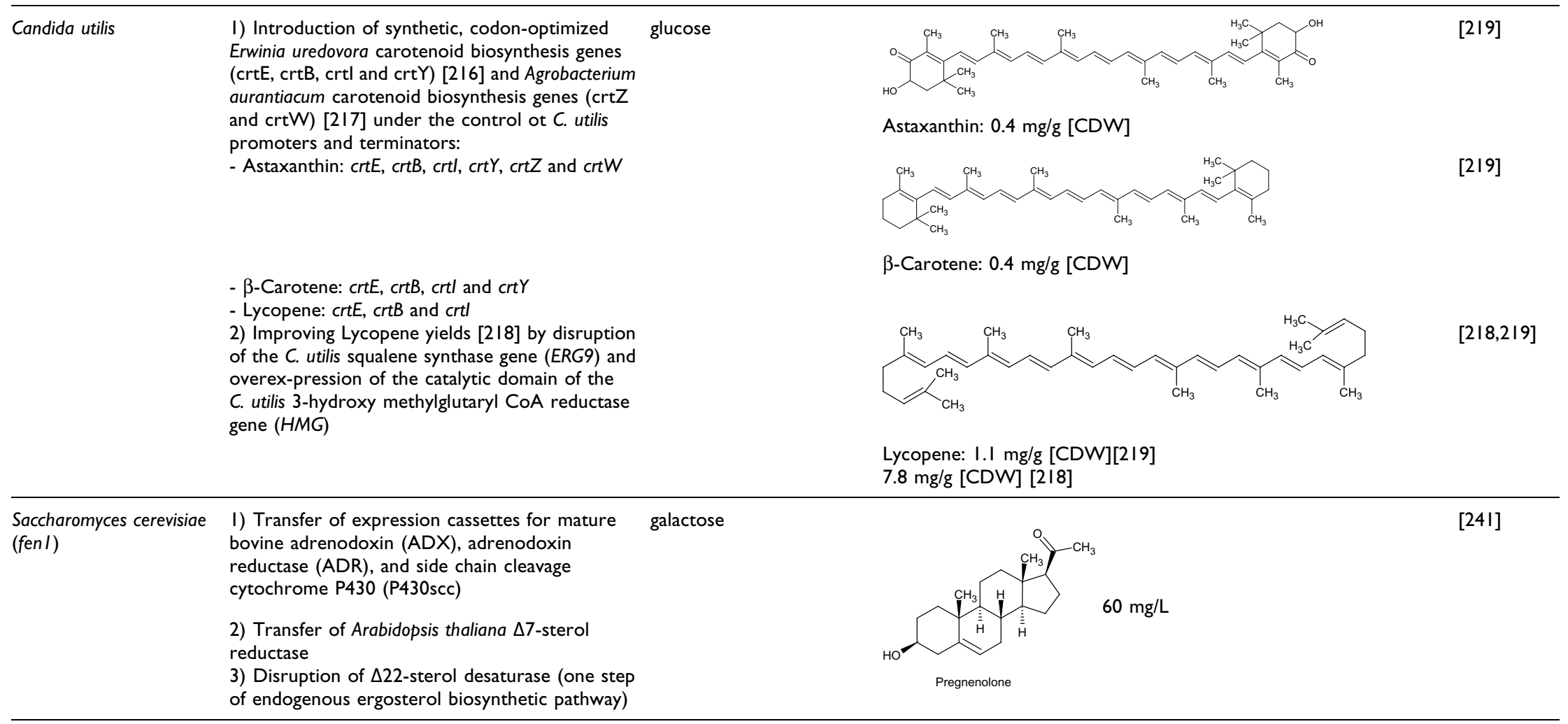




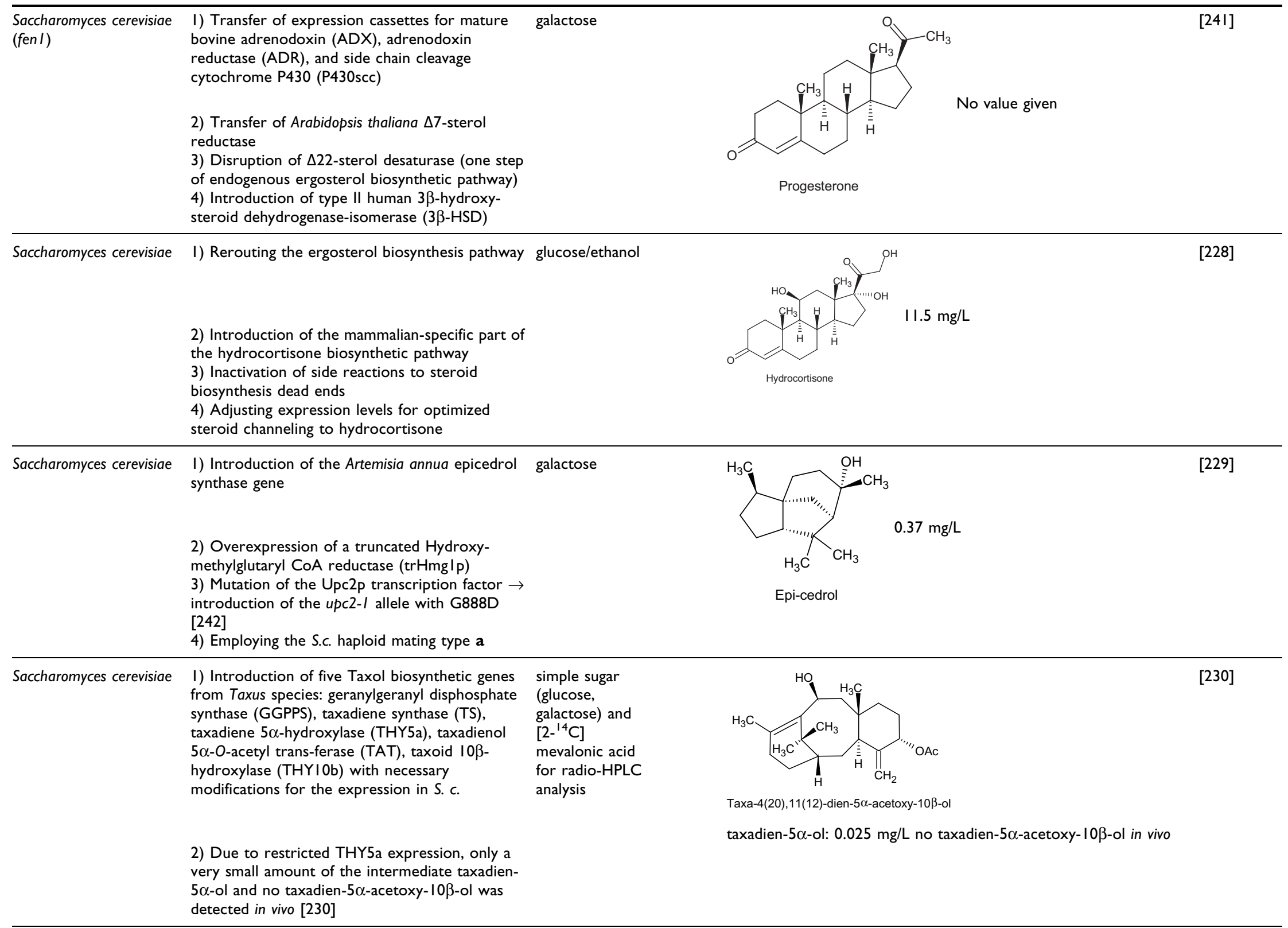


Table 5: Synthetic pathways based on isoprenoids, listed in chronological order (Continued)

Saccharomyces cerevisiae l) Engineering the farnesyl pyrophosphate (FPP) simple sugar biosynthetic pathway

2) Introduction of the Artemisia annua L amorphadiene synthase gene (FPP $\rightarrow$ amorphadiene)

3) Cloning the A. annua CYP7IAVI/CPR (3-step oxidation: amorphadiene $\rightarrow$ artemisinic acid)

\begin{tabular}{|c|c|}
\hline & $\begin{array}{l}\text { 2) Introduction of the Artemisia annua } \mathrm{L} \\
\text { amorphadiene synthase gene (FPP } \rightarrow \\
\text { amorphadiene) } \\
\text { 3) Cloning the A. annua CYP7IAVI/CPR (3-st } \\
\text { oxidation: amorphadiene } \rightarrow \text { artemisinic acid) }\end{array}$ \\
\hline Saccharomyces cerevisiae & $\begin{array}{l}\text { 1) Follow-up study of [226]: } \\
\text { 2) Engineering the pyruvate dehydrogenase } \\
\text { bypass (pyruvate to acetyl-CoA) by } \\
\text { overexpression of } \\
\text { - Salmonella acetyl-CoA synthetase variant } \\
\text { (L64IP) } \\
\text { - S. cerevisiae cytosolic acetaldehyde } \\
\text { dehydrogenase (ALD6) } \\
\text { - In strain S. cerevisiae EPY224 [226] } \\
\text { 3) Results: increased levels of mevalonate and } \\
\text { amorpha-4,II-diene }(\sim 130 \mathrm{mg} / \mathrm{L}) \text {; generally } \\
\text { applicable for isoprenoid production }\end{array}$ \\
\hline
\end{tabular}

glucose

$\sim 380 \mathrm{mg} / \mathrm{L}$

$\sim 130 \mathrm{mg} / \mathrm{L}$ 


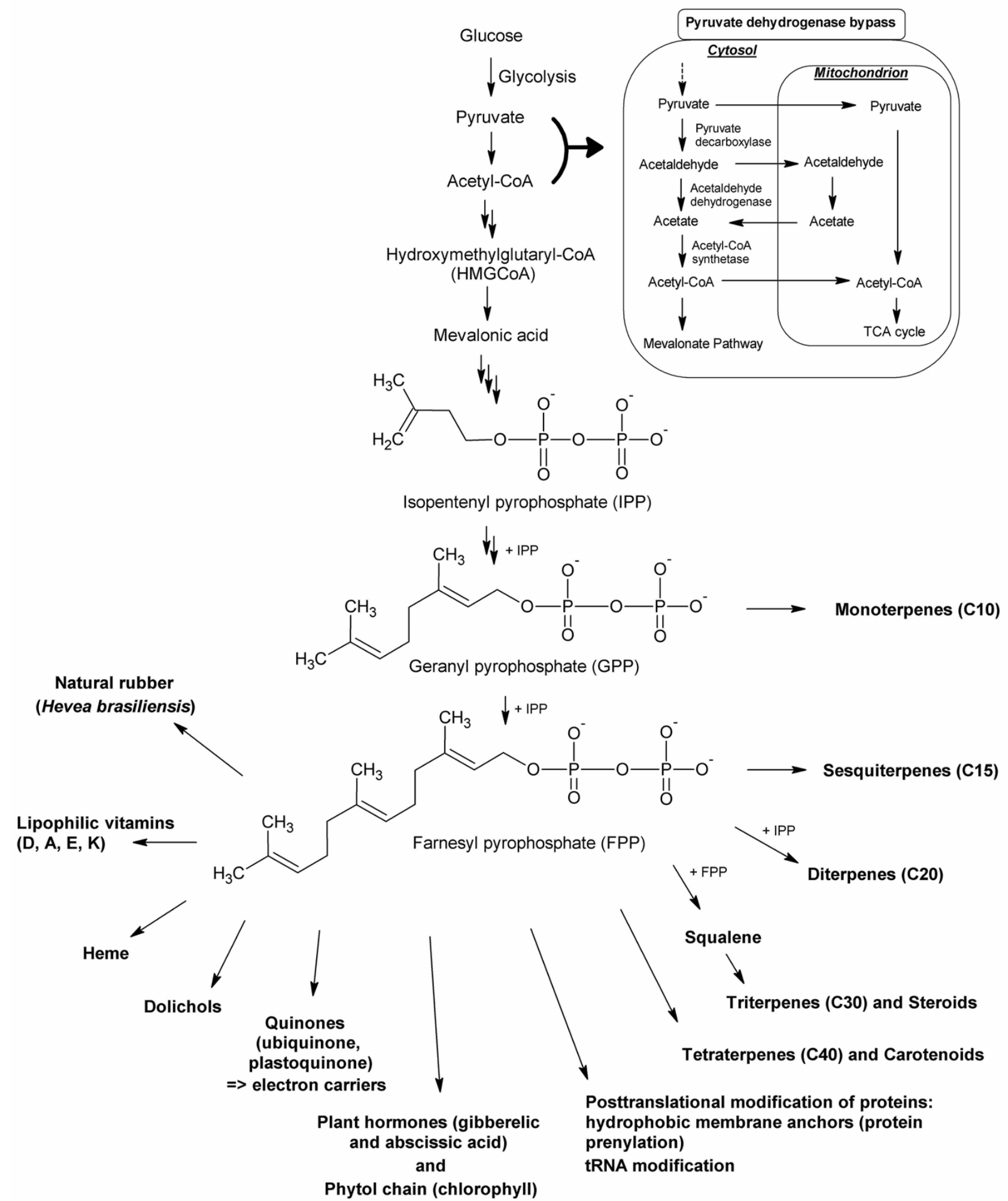

Figure 3

Overview of the biosynthetic pathway of farnesyl pyrophosphate - a pivotal intermediate for several essential pathways and various products [224]. Included is a schematic representation of the pyruvate dehydrogenase bypass whose engineering was shown to be effective for high-level isoprenoid production in S. cerevisiae [227]. 
The production of polyketide natural products in heterologous hosts, incapable of making polyketides on their own, requires first of all the introduction of a functional polyketide synthase (PKS). Similar to fatty acid biosynthesis, PKS is responsible for the condensation of acetyl-CoA and malonyl-CoA moieties [231]. Kealey et al. [232] and Wattanachaisaereekul et al. [231] engineered $S$. cerevisiae for the heterologous production of 6-methylsalicylic acid (1.7 and $0.2 \mathrm{~g} / \mathrm{L}$, respectively). Mutka et al. [215] first introduced pathways for the production of methylmalonyl-coenzyme A which constitutes a precursor for complex polyketides. Therefore two different routes were chosen, namely a propionylCoA-dependent and a propionyl-CoA-independent one. Furthermore, they achieved to demonstrate that the methylmalonyl-CoA, which was produced by the yeast strain, is further converted to a triketide lactone (Table 6 and Additional File 6, Entry 3). 0.5 to $1 \mathrm{mg} / \mathrm{L}$ of the triketide lactone were obtained with the propionyl-CoAdependent route.

Ro et al. [233] engineered S. cerevisiae in order to reconstitute the entry point of phenylpropanoid metabolism which should enable higher yields of flavonoids from yeast. Therefore, the Populus sp. enzymes phenylalanine ammonia lyase (isoform PAL2 and PAL4, respectively), cinnamate 4-hydroxylase $(\mathrm{C} 4 \mathrm{H})$ and the cytochrome P450 reductase (CPR2) were introduced in the yeast strain. At the end, $\sim 3-10 \mathrm{mg} / \mathrm{L}$ of $p$-coumarate were obtained employing the triple-expressing strains. Lately, Vannelli et al. [234] reached $498 \mu \mathrm{M}(=82 \mathrm{mg} / \mathrm{L})$ of trans-p-hydroxycinnamic acid (= p-coumarate) with recombinant $S$. cerevisiae cells expressing the plant $\mathrm{C} 4 \mathrm{H}$ Cytochrome P-450 and Cytochrome P-450 reductase from Helianthus tuberosus - and the Rhodotorula glutinis phenylalanine ammonia lyase. The highest levels of $p$ coumarate were achieved in cultures growing on raffinose and supplemented with $1.0 \mathrm{mM}$ of L-phenylalanine.

Jiang et al. [235] employed S. cerevisiae for the biosynthesis of naringenin, the central precursor of various flavonoids. This was accomplished by the recombinant expression of one yeast and two plant enzymes, namely phenylalanine ammonia lyase from Rhodosporidium toruloides, 4-coumarate:coenzyme A ligase from Arabidopsis thaliana and chalcone synthase from Hypericum androsaemum. They obtained $\sim 7 \mathrm{mg} / \mathrm{L}$ of naringenin and $0.8 \mathrm{mg} / \mathrm{L}$ of pinocembrin (Table 6 and Additional File 6, Entry 6). Beekwilder et al. [236] cloned plant genes involved in the biosynthesis of raspberry ketone [4-(4-hydroxyphenyl)-butan-2-one] and thus constructed microbial strains for the synthesis of one of the most expensive flavor components. In this case, the recombinant yeast strain converted most of the precursor ( $p$-coumaric acid) into hydroxyphenyl-propionic acid and this hampered the proper detection of raspberry ketone by GC-MS. However, they achieved to construct a recombinant E. coli BL21 strain expressing tobacco 4CL2 (4-coumarate-coenzyme A ligase) and raspberry CHS (chalcone synthase from Rubus idaeus) which yielded in $5 \mathrm{mg} / \mathrm{L}$ of raspberry ketone. For this purpose, it was grown in a fermenter for $46 \mathrm{~h}$ and enzyme production was induced by the addition of IPTG and $p$-coumaric acid. In nature, raspberry ketone occurs in concentrations between 1 and $4 \mathrm{mg} / \mathrm{kg}$ raspberries [237].

Several groups also engineered Saccharomyces cerevisiae for the synthesis of the antioxidant resveratrol which can be found especially in red wine. In 2000, GonzálezCandelas et al. [161] already generated a recombinant yeast strain expressing the Candida molischiana bglN gene encoding for a $\beta$-glucosidase in the industrial wine yeast S. cerevisiae $\mathrm{T}_{73}$ (CECT1894). In wines produced by the transgenic yeast strain, the content of trans- and cisresveratrol, respectively, was elevated to $\geq 0.75 \mu \mathrm{M}$ compared to $\leq 0.25 \mu \mathrm{M}$ in wines made with the wildtype. Then, Becker et al. [238] reported for the first time the reconstruction of a biochemical pathway for resveratrol biosynthesis in S. cerevisiae cells. However, only low levels of resveratrol $(\sim 1.5 \mu \mathrm{g} / \mathrm{L})$ resulted employing a recombinant $S$. cerevisiae strain co-expressing the coenzyme-A ligase from a hybrid poplar and the grapevine resveratrol synthase gene (Table 6 and Additional File 6, Entry 8). In 2006, Beekwilder et al. [239] succeeded in producing significantly higher amounts of resveratrol with engineered yeast strains $(\sim 6 \mathrm{mg} / \mathrm{L})$. They introduced the 4-coumarate:coenzyme A ligase (4CL) from Nicotiana tabacum cv. Samsun and the stilbene synthase (STS) from Vitis vinifera into S. cerevisiae CEN.PK 113-3b. Using the same biosynthetic genes, the recombinant yeast production strain was not much less efficient compared to an $E$. coli production strain $(\sim 16 \mathrm{mg} / \mathrm{L})$. Regarding the application in human nutrition, the food-grade status of yeast is a great advantage over E. coli.

Finally, Branduardi et al. [240] engineered S. cerevisiae for the biosynthesis of L-ascorbic acid (= vitamin C) starting from D-glucose. They cloned and expressed five different genes under the control of the S. cerevisiae TPI promoter, namely the gene encoding for the Arabidopsis thaliana mannose epimerase, the gene for the A. thaliana myo-inositol phosphatase/L-galactose-1-P-phosphatase, the L-fucose guanylyl-transferase from Rattus norvegicus, the A. thaliana L-galactose dehydrogenase and the $S$. cerevisiae D-arabinono-1,4-lactone oxidase in order to prevent a bottleneck at the end of the pathway. The best conversion yielded in $>0.1 \mathrm{mg} / \mathrm{L} / \mathrm{OD}$ L-ascorbic acid. In addition, they found out that intracellular accumulation 


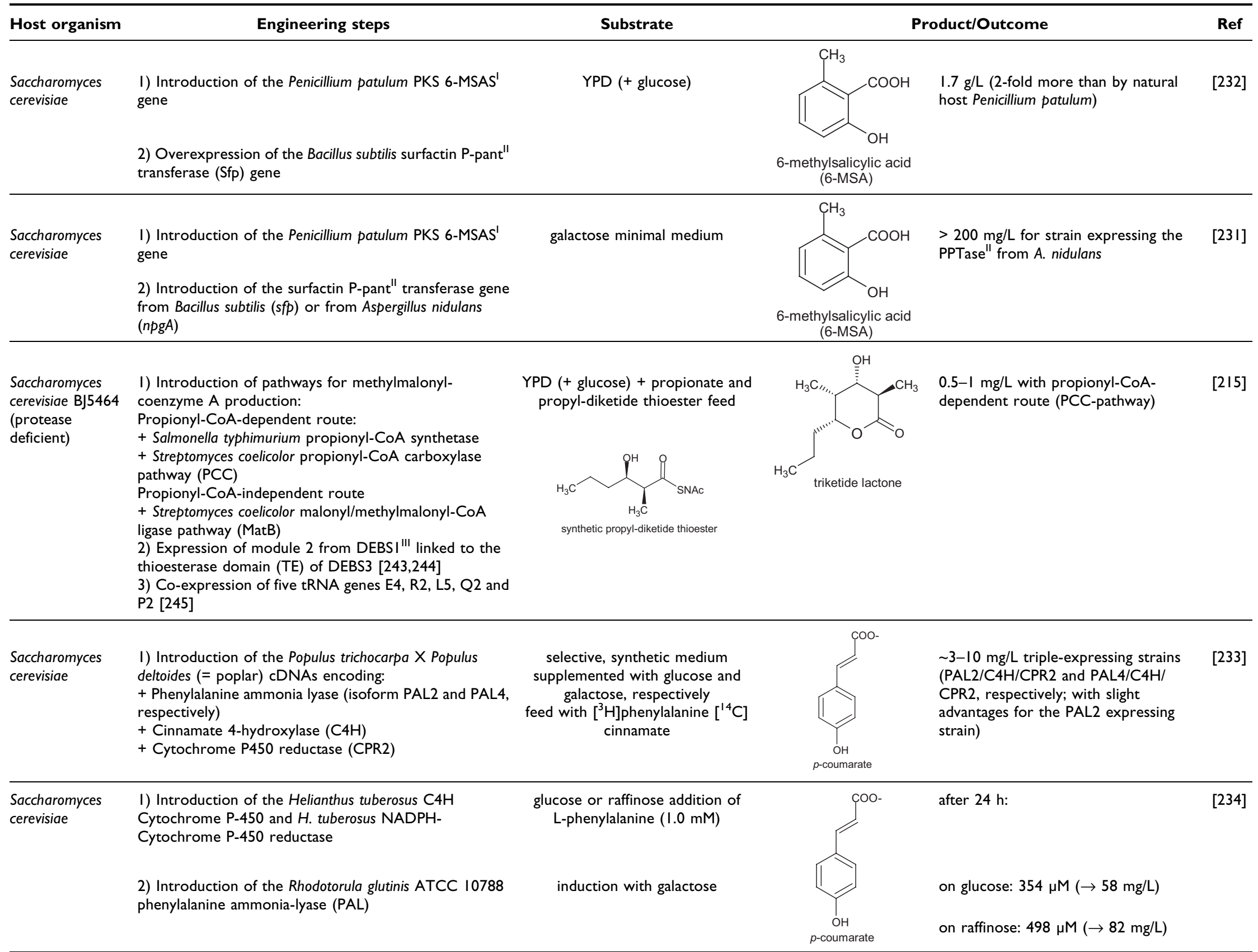

(isoform PAL2 and PAL4,

] $]$ phenylalanine $\left[{ }^{14} \mathrm{C}\right]$

YPD $(+$ glucose) + propionate and

Propionyl-CoA-dependent route:

(MatB)
(PPR2 4 /CPR2 and PAL4/C4H/

dvantages for the PAL2 expressing

strain) 
Table 6: Synthetic pathways for polyketide and flavonoid synthesis (Continued)

\begin{tabular}{|c|c|c|c|c|c|}
\hline $\begin{array}{l}\text { Saccharomyces } \\
\text { cerevisiae } \mathrm{AH} 22\end{array}$ & $\begin{array}{l}\text { I) Introduction of the phenylpropanoid pathway: } \\
\text { - Rhodosporidium toruloides phenylalanine ammonia lyase } \\
\text { (PAL) } \\
\text { - Arabidopsis thaliana 4-coumarate:coenzyme } \mathrm{A}(\mathrm{CoA}) \text { ligase } \\
(4 C L) \\
\text { - Hypericum androsaemum chalcone synthase }(\mathrm{CHS})\end{array}$ & $\begin{array}{c}\text { YPD (+ glucose }) \text { and YPL } \\
(+ \text { galactose })\end{array}$ & 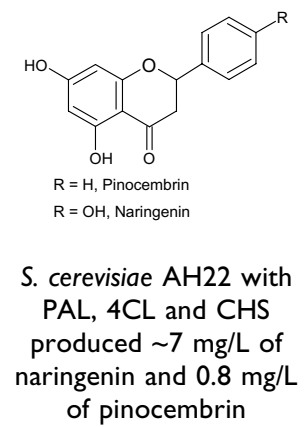 & & [235] \\
\hline $\begin{array}{l}\text { Saccharomyces } \\
\text { cerevisiae YPH499 }\end{array}$ & $\begin{array}{l}\text { I) Introduction of the chalcone synthase (CHS) from ripe } \\
\text { raspberry (Rubus idaeus) or a variant thereof (CHS } \\
\text { L2 I4I-F2 I5L) } \\
\text { 2) Introduction of the tobacco 4-coumarate-coenzyme A } \\
\text { ligase }(4 \mathrm{CL})\end{array}$ & $\begin{array}{l}\text { YPGal-medium (induction with } \\
\text { galactose) } \\
\text { addition of } p \text {-coumaric acid (3 mM) }\end{array}$ & pberry ketone & $\begin{array}{l}\text { raspberry fruit: } 1-4 \mathrm{mg} / \mathrm{kg} \\
\text { recombinant E. coli: } 5 \mathrm{mg} / \mathrm{L} \\
\text { recombinant S. cerevisiae: no proper } \\
\text { detection of raspberry ketone }\end{array}$ & $\begin{array}{l}{[237]} \\
{[236]} \\
{[236]}\end{array}$ \\
\hline $\begin{array}{l}\text { Saccharomyces } \\
\text { cerevisiae FY } 23\end{array}$ & $\begin{array}{l}\text { 1) Introduction of the coenzyme-A ligase } 4 C L 216 \text { gene } \\
\text { from hybrid poplar under the control of the yeast ADH } 2 \\
\text { gene promoter and terminator }(\rightarrow C A L I) \text { and } \\
\text { 2) the resveratrol synthase (VSTI) from grapevine (Vitis } \\
\text { vinifera) }\end{array}$ & $\begin{array}{l}\text { SCDL-medium }(0.67 \% \text { yeast } \\
\text { nitrogen base, } 0.8 \% \text { glucose and } \\
\text { required growth factors }) \text { with } 10 \\
\mathrm{mg} / \mathrm{L} p \text {-coumaric acid }\end{array}$ & $\begin{array}{l}\text { OH } \\
\text { recombinant } \mathrm{S} . \\
\text { cerevisiae: } \sim 1.5 \mu \mathrm{g} / \mathrm{L}\end{array}$ & & [238] \\
\hline $\begin{array}{l}\text { Saccharomyces } \\
\text { cerevisiae CEN. } \\
\text { PK I I3-3b (ura3 } \\
\text { his3) }\end{array}$ & $\begin{array}{l}\text { 1) Introduction of the 4-coumarate: coenzyme A (CoA) } \\
\text { ligase ( } 4 \text { CL2 gene - GenBank accession no. U50846) } \\
\text { from Nicotiana tabacum cv. Samsun } \\
\text { 2) Introduction of the STS gene from Vitis vinifera } \\
\text { encoding for the stilbene synthase (STS) }\end{array}$ & $\begin{array}{l}50 \mathrm{~mL} \text { yeast nitrogen base medium } \\
\text { supplemented with } 5 \mathrm{mM} \text { - } \\
\text { coumaric acid and } 2 \% \text { galactose to } \\
\text { induce gene expression }\end{array}$ & Resveratrol & $\begin{array}{l}\text { S. cerevisiae: } \sim 6 \mathrm{mg} / \mathrm{L} \\
\text { recomb. E. coli expressing the same } \\
\text { enzymes: } \sim 16 \mathrm{mg} / \mathrm{L}\end{array}$ & [239] \\
\hline
\end{tabular}

'PKS = polyketide synthase; 6-MSAS = 6-methylsalicylic acid synthase;

"PPTase $=$ P-pant transferase $=4$ '-phophopantetheinyl transferase;

IIIDEBS = deoxyerythronolide B synthase from Saccharopolyspora erythraea, a typical 'modular' polyketide synthase. 
of L-ascorbic acid led to an improved robustness of recombinant yeast strains towards different stress conditions, such as oxidative stress or the presence of organic and inorganic acids, respectively [240].

On the one hand, the above summarized attempts to reconstruct and engineer synthetic pathways in yeasts clearly depict the potential for the creation of future yeast whole-cell factories. The huge wealth of basic knowledge gained in the course of this work has already improved the understanding of more and more subcellular metabolic networks, their regulation and possible modulation. On the other hand, low yields reported for almost all complex products indicate that still major limitations exist which prevent todays yeast cell factories to be directly put to application. Examples with a high potential for an implementation in near future might be a further developed designer strain for the production of artemisinic acid or resveratrol. Especially for the applications in human nutrition, several yeast strains will provide interesting alternatives due to their food-grade status.

\section{Conclusion}

Without any doubt, Saccharomyces cerevisiae is the most thoroughly investigated eukaryotic microorganism and therefore the most frequently employed yeast strain in yeast-mediated whole-cell biotransformations. Regarding classical approaches, $S$. cerevisiae was almost always among the first biocatalysts chosen to solve the corresponding catalytic problem. However, finally only three types of enzymatic reactions were successfully performed with S. cerevisiae whole cells, namely oxidoreductase- (E.C. 1.-.---), hydrolase- (E.C. 3.-.---) and lyase(E.C. 4.-.-.) mediated biotransformations. The same is true for alternative yeast strains which were found due to biodiversity screening approaches. Alternative yeast strains employed for classical whole-cell biocatalysis are for example Candida sp., Cryptococcus sp., Geotrichum sp., Issatchenkia sp., Kloeckera sp., Kluyveromyces lactis, Pichia sp. (including Hansenula polymorpha = P. angusta), Rhodotorula sp., Rhodosporidium sp., Schizosaccharomyces pombe, Torulopsis sp., Trichosporon sp., Yarrowia lipolytica and Zygosaccharomyces rouxii.

Yeast strains employed for biotransformations in industry include Candida sp., Cryptococcus laurentii, Geotrichum candidum, Pichia sp., Rhodotorula rubra, Saccharomyces cerevisiae, Trigonopsis variabilis, and Zygosaccharomyces rouxii.

Up to now only wild-type yeast strains were employed for industrial applications except for Pichia pastoris strains expressing the phenylalanine dehydrogenase from Thermoactinomyces intermedius for the production of a chiral building block for Omapatrilat synthesis. Again, most of the industrial biotransformations catalyzed by yeast whole cells were oxidation or reduction reactions. However, three lyase-based reactions were encountered: $S$. cerevisiae for the production of (1R)-phenylacetylcarbinol; Rhodotorula rubra for the production of L-phenylalanine and Candida rugosa for $(R)$ - $\beta$-hydroxy-n-butyric and ( $R$ - $\beta$ - $\beta$-hydroxy-isobutyric acid production.

Regarding engineered yeast whole-cell biocatalysts, again, oxidoreductase reactions are favored. This also includes the engineering of more efficient cofactor regeneration systems whereas yeast surface display approaches focus on hydrolytic enzymes.

For every biocatalyst engineer, the construction and employment of synthetic pathways pose probably the greatest challenge as they require the interrelation of diverse fields of research. However, they also elucidate and indicate the catalytic potential and limits of yeast strains and the capability of metabolic engineering including available genetic tools. In future, investigations in all different fields related to whole-cell biocatalysis are required in order to expand the scope of valuable biocatalytic reactions.

\section{Competing interests}

The authors declare that they have no competing interests.

\section{Authors' contributions}

Both authors suggested the topic of this review. BP drafted the manuscript. AG revised it critically and gave final approval of the version to be published. All authors read and approved the final manuscript.

\section{Additional material}

Additional file 1
Table 1 .
Click here for file
[http://www.biomedcentral.com/content/supplementary/1475-
2859-7-25-S1.doc]
Additional file 2
Table 2 .
Click here for file
[http://www.biomedcentral.com/content/supplementary/1475-
2859-7-25-S2.doc]
Additional file 3
Table 3.
Click here for file
[http://www.biomedcentral.com/content/supplementary/1475-
2859-7-25-S3.doc]

[http://www.biomedcentral.com/content/supplementary/14752859-7-25-S1.doc]

\section{Additional file 2}

Table 2.

[http://www.biomedcentral.com/content/supplementary/14752859-7-25-S2.doc]

\section{Additional file 3}

Table 3.

[http://www.biomedcentral.com/content/supplementary/14752859-7-25-S3.doc] 


\section{Additional file 4}

Table 4.

Click here for file

[http://www.biomedcentral.com/content/supplementary/14752859-7-25-S4.doc]

\section{Additional file 5}

Table 5.

Click here for file

[http://www.biomedcentral.com/content/supplementary/14752859-7-25-S5.doc]

\section{Additional file 6}

\section{Table 6 .}

Click here for file

[http://www.biomedcentral.com/content/supplementary/14752859-7-25-S6.doc]

\section{Acknowledgements}

The authors thank Dr. Kirsten Schroer and Dr. Franz S. Hartner for the lively discussion of and valuable comments on the manuscript. We thank FFG, the Province of Styria, SFG and the City of Graz for financial support.

\section{References}

I. Delwen S: Ancient Egyptian Cereal Processing: Beyond the Artistic Record. Cambridge Archaeological Journal 1993, 276-283.

2. Delwen S: Investigation of Ancient Egyptian Baking and Brewing Methods by Correlative Microscopy. Science 1996, 273:488-490.

3. Ray J: The Oxford Encyclopedia of Ancient Egypt. T/s-the Times Literary Supplement 200I, 6 .

4. Barnett JA: Beginnings of microbiology and biochemistry: the contribution of yeast research. Microbiology-Sgm 2003, | 49:557-567.

5. Fischer $E$ and Thierfelder $\mathrm{H}$ : Verhalten der verschiedenen Zucker gegen reine Hefen. Ber Dtsch Chem Ges 1894, 27:203I-2037.

6. Henri V: Lois Général de l'Action des Diastases Paris: Hermann; 1903.

7. Michaelis L and Menten ML: Die Kinetik der Invertasewirkung. Biochem Z 19|3, 49:333-369.

8. Haldane JBS: Enzymes London: Longmans, Green; 1930.

9. Koshland DE: Application of A Theory of Enzyme Specificity to Protein Synthesis. Proceedings of the National Academy of Sciences of the United States of America 1958, 44:98-104.

10. Koshland DE: The Key-Lock Theory and the Induced Fit Theory. Angewandte Chemie-International Edition 1995, 33:2375-2378.

II. Monod J: The phenomenon of enzymatic adaptation and its bearing on problems of genetics and cellular differentiation. Growth 1947, I I:223-289.

12. Forsburg SL and Nurse P: Cell-Cycle Regulation in the Yeasts Saccharomyces cerevisiae and Schizosaccharomyces pombe. Annual Review of Cell Biology 1991, 7:227-256.

13. Hartwell LH: 25 Years of Cell-Cycle Genetics. Genetics 199I, I 29:975-980.

14. Kurtzman CP: Molecular Taxonomy of the Yeasts. Yeast 1994, 10:1727-1740.

15. Boekhout T and Kurtzman CP: Principles and methods used in yeast classification, and an overview of currently accepted yeast genera. Nonconventional Yeasts in biotechnology. A Handbook Berlin, Heidelberg: Springer-Verlag: Wolf K 1996, I-99.

16. Hibbett DS, Binder M, Bischoff JF, Blackwell M, Cannon PF, Eriksson OE, Huhndorf S, James T, Kirk PM and Lucking R, et al: A higher-level phylogenetic classification of the Fungi. Mycological Research 2007, III:509-547.

17. Barnett JA: A history of research on yeasts 8: taxonomy. Yeast 2004, 21: | |4|-1| 93.

18. Walker GM: Introduction to Yeasts. Yeast Physiology and Biotechnology Chichester: John Wiley \& Sons Ltd; 1998, I-9.
19. The Yeasts - A Taxonomic Study: Fourth Revised and Enlarged Edition Amsterdam: Elsevier; 1997.

20. Scannell DR, Butler G and Wolfe KH: Yeast genome evolution the origin of the species. Yeast 2007, 24:929-942.

21. Neuberg C, Hirsch J and Reinfurth E: The three fermentationforms of sugar, their coherences and balance. Biochemische Zeitschrift 1920, 105:307-336.

22. Neuberg $C$ and Hirsch J: The carbon chain of attached enzymes (carboligase). Biochemische Zeitschrift 1921, II5:282-310.

23. Neubauer $O$ and Fromherz $K$ : The decomposition of amino acids in yeast fermentation. Hoppe-Seylers Zeitschrift fur Physiologische Chemie 1911, 70:326-350.

24. Faber K: Biotransformations in Organic Chemistry - A Textbook Berlin, Heidelberg: Springer-Verlag; 2004.

25. Yamada $\mathrm{H}$ and Shimizu S: Microbial and Enzymatic Processes for the Production of Biologically and Chemically Useful Compounds. Angewandte Chemie-International Edition in English 1988, 27:622-642.

26. Fujio T: Minimum genome factory: innovation in bioprocesses through genome science. Biotechnology and Applied Biochemistry 2007, 46: | 45-146.

27. Mizoguchi $\mathrm{H}$, Mori $\mathrm{H}$ and Fujio T: Escherichia coli minimum genome factory. Biotechnology and Applied Biochemistry 2007, 46:157-167.

28. Ara K, Ozaki K, Nakamura K, Yamane K, Sekiguchi J and Ogasawara N: Bacillus minimum genome factory: effective utilization of microbial genome information. Biotechnology and Applied Biochemistry 2007, 46:169-178.

29. Giga-Hama Y, Tohda H, Takegawa K and Kumagai H: Schizosoccharomyces pombe minimum genome factory. Biotechnology and Applied Biochemistry 2007, 46:147-155.

30. Servi S: Baker's yeast as a reagent in organic synthesis. Synthesis-Stuttgart 1990, I-25.

31. Windisch W: Wochenschrift für Brauerei 1898, 15:189.

32. Lintner $\mathrm{CJ}$ and von Liebig $\mathrm{HJ}$ : The reduction of furfural through yeast in alcoholic fermentation. Hoppe-Seylers Zeitschrift fur Physiologische Chemie 1911, 72:449-454.

33. Neuberg C: Biochemical Reductions at the Expense of Sugars. Advances in Carbohydrate Chemistry 1949, 4:75-II7.

34. Csuk R and Glanzer BI: Bakers Yeast Mediated Transformations in Organic Chemistry. Chemical Reviews 1991, 91:49-97.

35. Kometani T, Yoshii $H$ and Matsuno R: Large-scale production of chiral alcohols with baker's yeast. Journal of Molecular Catalysis B: Enzymatic 1996, I:45-52.

36. Nakamura K, Yamanaka R, Matsuda $T$ and Harada T: Recent developments in asymmetric reduction of ketones with biocatalysts. Tetrahedron-Asymmetry 2003, | 4:2659-268I.

37. Goldberg K, Schroer K, Lutz S and Liese A: Biocatalytic ketone reduction - a powerful tool for the production of chiral alcohols - part II: whole-cell reductions. Applied Microbiology and Biotechnology 2007, 76:249-255.

38. Stewart JD: Dehydrogenases and transaminases in asymmetric synthesis. Current Opinion in Chemical Biology 2001, 5:120-129.

39. Mueller M, Wolberg M, Schubert $T$ and Hummel W: Enzyme catalyzed regio- and enantioselective ketone reductions. Advances in Biochemical Engineering/Biotechnology 2005, 92:26 I-287.

40. Kula M-R and Kragl U: Dehydrogenases in the synthesis of chiral compounds. Stereoselective Biocatalysis New York: Marcel Dekker: Patel RN 2000, 839-866.

41. Nakamura K, Matsuda T and Harada T: Chiral synthesis of secondary alcohols using Geotrichum candidum. Chirality 2002, 14:703-708.

42. Nakamura $\mathrm{K}$ and Matsuda $\mathrm{T}$ : Reduction of ketones. Enzyme Catalysis in Organic Synthesis Weinheim: Wiley-VCH: Drauz K, Waldmann H 2002, 3:99I-1047.

43. Patel RN: Biocatalytic synthesis of intermediates for the synthesis of chiral drug substances. Current Opinion in Biotechnology 200 I, I 2:587-604.

44. Prelog V: Specification of the stereospecificity of some oxidoreductases by diamond lattice sections. Pure and Applied Chemistry 1964, 9:119-130.

45. Macleod R, Prosser H, Fikentscher L, Mosher HS and Lanyi J: Asymmetric Reductions 12. Stereoselective Ketone Reductions by Fermenting Yeast. Biochemistry 1964, 3:838.

46. Chen CS, Zhou BN, Girdaukas G, Shieh WR, Vanmiddlesworth F, Gopalan AS and Sih C): Stereochemical Control of Yeast Reductions .2. Quantitative Treatment of the Kinetics of Competing Enzyme-Systems for A Single Substrate. Bioorganic Chemistry 1984, 12:98-117. 
47. Rodriguez S, Kayser $M$ and Stewart JD: Improving the stereoselectivity of baker's yeast reductions by genetic engineering. Organic Letters 1999, I: I I53-II55.

48. Mewes HW, Albermann K, Bahr M, Frishman D, Gleissner A, Hani J, Heumann K, Kleine K, Maierl A and Oliver SG, et al: Overview of the yeast genome. Nature 1997, 387:7-8.

49. Goffeau A, Barrell BG, Bussey H, Davis RW, Dujon B, Feldmann H, Galibert F, Hoheisel JD, Jaca $C$ and Johnston M, et al: Life with 6000 genes. Science 1996, 274:546.

50. Zhou BN, Gopalan AS, Vanmiddlesworth F, Shieh WR and Sih C) Stereochemical Control of Yeast Reductions .I. Asymmetric Synthesis of L-Carnitine. Journal of the American Chemical Society 1983, 105:5925-5926.

5I. Ehrler J, Giovannini F, Lamatsch B and Seebach D: Stereoselectivity of Yeast Reductions - An Improved Procedure for the Preparation of Ethyl (S)-3-Hydroxybutanoate and (S)-2Hydroxymethylbutanoate. Chimia 1986, 40:I72-I73.

52. Nakamura K, Kawai $Y$ and Ohno A: Stereochemical Control in Microbial Reduction I3. A Novel Method to Synthesize (L)Beta-Hydroxyl Esters by the Reduction with Baker's Yeast. Tetrahedron Letters 1990, 31:267-270.

53. Jayasinghe LY, Smallridge AJ and Trewhella MA: The Yeast Mediated Reduction of Ethyl Acetoacetate in Petroleum Ether. Tetrahedron Letters 1993, 34:3949-3950.

54. DArrigo P, Fantoni GP, Servi $S$ and Strini A: The effect of absorbing resins on substrate concentration and enantiomeric excess in yeast reduction. Tetrahedron-Asymmetry 1997, 8:2375-2379.

55. Pfruender $H$, Jones $R$ and Weuster-Botz $D$ : Water immiscible ionic liquids as solvents for whole cell biocatalysis. Journal of Biotechnology 2006, I 24:182-190.

56. Lagos FM, Del Campo C, Llama EF and Sinisterra JV: New yeast strains for enantioselective production of halohydrin precursor of (S)-propranolol. Enzyme and Microbial Technology 2002, 30:895-901.

57. Dehli JR and Gotor V: Dynamic kinetic resolution of 2oxocycloalkanecarbonitriles: Chemoenzymatic syntheses of optically active cyclic beta- and gamma-amino alcohols. Journal of Organic Chemistry 2002, 67:6816-6819.

58. Enders D, Vicario JL, Job A, Wolberg $M$ and Muller M: Asymmetric total synthesis of (-)-callystatin A and (-)-20-epi-callystatin A employing chemical and biological methods. Chemistry- $A$ European Journal 2002, 8:4272-4284.

59. Bertau $M$ and Burli $M$ : Enantioselective microbial reduction with baker's yeast on an industrial scale. Chimia 2000, 54:503-507.

60. Barbieri C, Caruso E, D'Arrigo P, Fantoni GP and Servi S: Chemoenzymatic synthesis of $(R)$ - and (S)-3,4-dichlorophenylbutanolide intermediate in the synthesis of sertraline. TetrahedronAsymmetry 1999, 10:3931-3937.

61. Matsuyama A, Yamamoto $\mathrm{H}$, Kawada $\mathrm{N}$ and Kobayashi $\mathrm{Y}$ : Industrial production of $(R)-I, 3$-butanediol by new biocatalysts. Journal of Molecular Catalysis B: Enzymatic 200 I, I I:5 I3-52 I.

62. Soni $P$ and Banerjee UC: Biotransformations for the production of the chiral drug (S)-Duloxetine catalyzed by a novel isolate of Candida tropicalis. Applied Microbiology and Biotechnology 2005 , 67:77I-777.

63. Etschmann MMW and Schrader J: An aqueous-organic twophase bioprocess for efficient production of the natural aroma chemicals 2-phenylethanol and 2-phenylethylacetate with yeast. Applied Microbiology and Biotechnology 2006, 71:440-443.

64. Stark D, Munch T, Sonnleitner B, Marison IW and von Stockar U: Extractive bioconversion of 2-phenylethanol from L-phenylalanine by Saccharomyces cerevisiae. Biotechnology Progress 2002 , I 8:514-523

65. Kroutil W, Mang H, Edegger $\mathrm{K}$ and Faber $\mathrm{K}$ : Recent advances in the biocatalytic reduction of ketones and oxidation of secalcohols. Current Opinion in Chemical Biology 2004, 8: I20-126.

66. Yasohara $Y$, Kizaki N, Hasegawa J, Wada $M$, Kataoka $M$ and Shimizu S: Stereoselective reduction of alkyl 3-oxobutanoate by carbonyl reductase from Candida magnoliae. TetrahedronAsymmetry 2001, 12:1713-1718.

67. Kizaki $N$, Yasohara $Y$, Hasegawa I. Wada $M$, Kataoka $M$ and Shimizu S: Synthesis of optically pure ethyl (S)-4-chloro-3hydroxybutanoate by Escherichia coli transformant cells coexpressing the carbonyl reductase and glucose dehydrogenase genes. Applied Microbiology and Biotechnology 2001, 55:590-595.
68. Stewart JD: Organic transformations catalyzed by engineered yeast cells and related systems. Current Opinion in Biotechnology 2000, I I:363-368.

69. Kataoka M, Kita K, Wada M, Yasohara Y, Hasegawa J and Shimizu S: Novel bioreduction system for the production of chiral alcohols. Applied Microbiology and Biotechnology 2003, 62:437-445.

70. Warburg $O$ and Christian $W$ : Yellow enzyme and its effects. Biochemische Zeitschrift 1933, 266:377-4II.

7I. Stuermer R, Hauer B, Hall $M$ and Faber K: Asymmetric bioreduction of activated $C=C$ bonds using enoate reductases from the old yellow enzyme family. Current Opinion in Chemical Biology 2007, I I:203-2I3.

72. Tischer $W$, Bader $J$ and Simon $H$ : Purification and some properties of a hitherto-unknown enzyme reducing the carbon-carbon double-bond of alpha,beta-unsaturated carboxylate anions. European Journal of Biochemistry 1979 , 97:103-I 12 .

73. Leuenberger HGW, Boguth W, Widmer E and Zell R: Synthesis of Optically Active Natural Carotenoids and Structurally Related Compounds . I. Synthesis of Chiral Key Compound (4R, 6R)-4-Hydroxy-2,2,6-Trimethylcyclohexanone. Helvetica Chimica Acta 1976, 59:1832-1849.

74. Liese A, Seelbach K, Buchholz A and Haberland J: Processes. Industrial Biotransformations Weinheim: Wiley-VCH: Liese A, Seelbach K, Wandrey C 22006, |47-5I4.

75. Kawai $Y$, Inaba $Y$ and Tokitoh N: Asymmetric reduction of nitroalkenes with baker's yeast. Tetrahedron-Asymmetry 200I, 1 2:309-318.

76. Ohta $\mathrm{H}$, Kobayashi $\mathrm{N}$ and Ozaki K: Asymmetric Reduction of Nitro Olefins by Fermenting Baker's Yeast. Journal of Organic Chemistry 1989, 54:1802-1804.

77. Leuenberger HGW, Boguth $W$, Barner R, Schmid $M$ and Zell R: Total Synthesis of Natural Alpha-Tocopherol I. Preparation of Bifunctional Optically-Active Precursors for the Synthesis of the Side-Chain by Means of Microbiological Transformations. Helvetica Chimica Acta 1979, 62:455-463.

78. Cantello BCC, Eggleston DS, Haigh D, Haltiwanger RC, Heath CM, Hindley RM, Jennings KR, Sime JT and Woroniecki SR: Facile Biocatalytic Reduction of the Carbon-Carbon Double-Bond of 5-Benzylidenethiazolidine-2,4-Diones - Synthesis of (+/-)5-(4-(2-[Methyl(2-Pyridyl)Amino]Ethoxy)Benzyl)Thiazolidine-2,4-Dione (Brl-49653), Its (R)-(+)-Enantiomer and Analogs. Journal of the Chemical Society-Perkin Transactions I I994, 3319-3324.

79. Mori A, Ishiyama I, Akita H, Suzuki K, Mitsuoka T and Oishi T: Reduction of Nitroolefin Using Microorganisms. Chemical \& Pharmaceutical Bulletin 1990, 38:3449-345I.

80. Wada M, Yoshizumi A, Noda Y, Kataoka M, Shimizu S, Takagi H and Nakamori S: Production of a doubly chiral compound, (4R, 6R)-4-hydroxy-2,2,6-trimethylcyclohexanone, by two-step enzymatic asymmetric reduction. Applied and Environmental Microbiology 2003, 69:933-937.

81. Swiderska MA and Stewart JD: Stereoselective enone reductions by Saccharomyces carlsbergensis old yellow enzyme. Journal of Molecular Catalysis B: Enzymatic 2006, 42:52-54.

82. Kataoka M, Kotaka A, Thiwthong R, Wada M, Nakamori S and Shimizu S: Cloning and overexpression of the old yellow enzyme gene of Candida macedoniensis, and its application to the production of a chiral compound. Journal of Biotechnology 2004, I | 4: I-9.

83. Tani $\mathrm{Y}$, Ogata $\mathrm{K}$, Nishikaw $\mathrm{H}$ and Miya $\mathrm{T}$ : Microbial metabolism of methanol I. Formation and crystallization of methanoloxidizing enzyme in a methanol-utilizing yeast, Kloeckera sp. No 2201. Agricultural and Biological Chemistry 1972, 36:68.

84. Tani Y, Miya T and Ogata K: Microbial metabolism of methanol 2. Properties of crystalline alcohol oxidase from Kloeckera sp. No 220 I. Agricultural and Biological Chemistry 1972, 36:76.

85. Fujii $\mathrm{T}$ and Tonomura K: Oxidation of Methanol, Formaldehyde and Formate by a Candida Species. Agricultural and Biological Chemistry 1972, 36:2297-2306.

86. Nestl BM, Bodlenner A, Stuermer $R$, Hauer B, Kroutil $W$ and Faber K: Biocatalytic racemization of synthetically important functionalized alpha-hydroxyketones using microbial cells. Tetrahedron-Asymmetry 2007, I 8: |465-|474.

87. Walker AJ: Asymmetric Carbon-Carbon Bond Formation Using Sulfoxide-Stabilized Carbanions. Tetrahedron-Asymmetry 1992, 3:961-998.

88. Chen G, Kayser MM, Mihovilovic MD, Mrstik ME, Martinez CA and Stewart JD: Asymmetric oxidations at sulfur catalyzed by 
engineered strains that overexpress cyclohexanone monooxygenase. New Journal of Chemistry 1999, 23:827-832.

89. Patel RN, Hou CT, Laskin Al, Derelanko P and Felix A: Oxidation of Secondary Alcohols to Methyl Ketones by Yeasts. Applied and Environmental Microbiology 1979, 38:219-223.

90. Beecher J, Brackenridge I, Roberts SM, Tang J and Willetts AJ: Oxidation of Methyl p-Tolyl Sulfide with Baker's Yeast Preparation of A Synthon of the Mevinic Acid-Type Hypocholestemic Agents. Journal of the Chemical Society-Perkin Transactions I 1995, |64I-1643.

91. Buist PH, Marecak DM, Partington ET and Skala P: Enantioselective Sulfoxidation of A Fatty Acid Analog by Baker's Yeast. Journal of Organic Chemistry 1990, 55:5667-5669.

92. Nestl BM, Voss CV, Bodlenner A, Ellmer-Schaumberger $U$, Kroutil $\mathrm{W}$ and Faber K: Biocatalytic racemization of secalcohols and alpha-hydroxyketones using lyophilized microbial cells. Applied Microbiology and Biotechnology 2007, 76: $1001-1008$.

93. Titu $D$ and Chadha A: Preparation of optically pure alkyl 3(hetero-2-yl)-3-hydroxypropanoates by Candida parapsilosis ATCC 7330 mediated deracemisation. Journal of Molecular Catalysis B: Enzymatic 2008, 52-3:168-172.

94. Mamoli L: The behaviour of estrogen hormones with the effect of fermenting yeast: Biochemistry transformation of oestrogen ester in alpha- estradiol. Berichte der Deutschen Chemischen Gesellschaft 1938, 71:2696-2698.

95. Achstetter $\mathrm{T}$ and Wolf $\mathrm{DH}$ : Proteinases, proteolysis and biological control in the yeast Saccharomyces cerevisiae. Yeast 1985, I:139-157.

96. Glanzer BI, Faber K and Griengl H: Microbial Resolution of OAcetylpantoyl Lactone. Enzyme and Microbial Technology 1988, 10:689-690.

97. Shimizu $H$, Ogawa J, Kataoka $M$ and Kobayashi M: Screening of novel microbial enzymes for the production of biologically and chemically useful compounds. Advances in biochemical engineering biotechnology, New enzymes for organic synthesis New York: Springer: Scheper T 1997, 58:45-88.

98. Robins $\mathrm{K}$ and Gilligan T: Microbial resolution of racemic 2,2dimethylcyclopropanecarboxamide in the manufacture of the acid. (EP 502525 Al) 1992.

99. Crosby J: Synthesis of Optically Active Compounds - A Large Scale Perspective. Tetrahedron 199I, 47:4789-4846.

100. Sheldon RA: Chirotechnology New York: Marcel Dekker Inc; 1993.

10I. May O, Verseck S, Bommarius A and Drauz K: Development of dynamic kinetic resolution processes for biocatalytic production of natural and nonnatural L-amino acids. Organic Process Research \& Development 2002, 6:452-457.

102. Labuschagne $M$, Botes $A L$ and Albertyn J: Cloning and sequencing of an epoxide hydrolase gene from Rhodosporidium paludigenum. Dna Sequence 2004, 15:202-205.

103. Crout DHG, Dalton H, Hutchinson DW and Miyagoshi M: Studies on Pyruvate Decarboxylase - Acyloin Formation from Aliphatic, Aromatic and Heterocyclic Aldehydes. Journal of the Chemical Society-Perkin Transactions I 1991, 1329-1334.

104. Pohl M: Protein design on pyruvate decarboxylase (PDC) by site-directed mutagenesis. New enzymes for organic synthesis Berlin, Heidelberg, New York: Springer: Scheper T 1999, 15.

105. Fuganti $C$ and Grasselli P: Transformations of non-conventional substrates by fermenting baker's yeast: production of optically active methyl-diols from aldehydes. Chemistry \& Industry (London, UK) 1977, 983.

106. Fuganti $C$ and Grasselli P: Baker's yeast-mediated synthesis of natural products. Biocatalysis in Agricultural Biotechnology Washington DC: ACS Symp Ser, Am Chem Soc: Whitaker JR, Sonnet PE 1989,359

107. Fuganti $C$ and Grasselli P: Synthesis of the C-14 Chromanyl Moiety of Natural Alpha-Tocopherol (Vitamin E). Journal of the Chemical Society-Chemical Communications 1982, 205-206.

108. Vassilev VP, Uchiyama T, Kajimoto T and Wong CH: L-Threonine aldolase in organic synthesis - preparation of novel betahydroxy-alpha-amino acids. Tetrahedron Letters 1995, 36:408I-4084.

109. Smith PF and Hendlin D: Mechanism of Phenylacetylcarbinol Synthesis by Yeast. Journal of Bacteriology 1953, 65:440-445.

110. Cheetham PSJ: Case studies in applied biocatalysis - from ideas to products. Applied Biocatalysis Harwood, USA: Academic Publishers: Cabral JMS, Best D, Boross L, Tramper J 1994, 87-89.

III. Kieslich K: Biotransformations of Industrial Use. Acta Biotechnologica 1991, I 1:559-570.
112. Hasegawa J, Ogura M, Kanema $H$, Noda $N$, Kawaharada $H$ and Watanabe K: Production of D- $\beta$-hydroxyisobutyric acid from isobutyric acid by Candida rugosa and its mutant. Journal of Fermentation Technology 1982, 60:50 I-508.

113. Zmijewski MJ, Vicenzi J, Landen BE, Muth W, Marler $P$ and Anderson $B$ : Enantioselective reduction of 3,4-methylenedioxyphenylacetone using Candida famata and Zygosaccharomyces rouxii. Applied Microbiology and Biotechnology 1997, 47:162-166.

114. Anderson BA, Hansen MM, Harkness AR, Henry CL, Vicenzi JT and Zmijewski MJ: Application of A Practical Biocatalytic Reduction to An Enantioselective Synthesis of the 5H-2,3-Benzodiazepine Ly300 164. Journal of the American Chemical Society 1995, I 17:12358-12359.

I15. Vicenzi JT, Zmijewski MJ, Reinhard MR, Landen BE, Muth WL and Marler PG: Large-scale stereoselective enzymatic ketone reduction with in situ product removal via polymeric adsorbent resins. Enzyme and Microbial Technology 1997, 20:494-499.

116. Zaks $A$ and Dodds DR: Application of biocatalysis and biotransformations to the synthesis of pharmaceuticals. Drug Discovery Today 1997, 2:5I3-53I.

117. Patel RN: Stereoselective biotransformations in synthesis of some pharmaceutical intermediates. Advances in Applied Microbiology 1997, 43:9|-|40.

I18. Patel RN, Mcnamee CG, Banerjee A, Howell JM, Robison RS and Szarka LJ: Stereoselective reduction of $\beta$-keto-esters by Geotrichum candidum. Enzyme and Microbial Technology 1992, | 4:73|-738.

119. Chartrain M, Roberge C, Chung J, McNamara J, Zhao DL, Olewinski R, Hunt G, Salmon P, Roush D and Yamazaki S, et al Asymmetric bioreduction of (2-(4-nitro-phenyl)-N-(2-oxo-2pyridin-3-yl-ethyl)-acetamide) to its corresponding $(R)$ alcohol $[(R)-N-(2$-hydroxy-2-pyridin-3-yl-ethyl)-2-(4-nitro-phenyl)-acetamide] by using Candida sorbophila MY 1833. Enzyme and Microbial Technology 1999, 25:489-496.

120. Chung JYL, Ho G], Chartrain M, Roberge C, Zhao DL, Leazer J, Farr R, Robbins M, Emerson $\mathrm{K}$ and Mathre DJ, et al: Practical chemoenzymatic synthesis of a 3-pyridylethanolamino beta3 adrenergic receptor agonist. Tetrahedron Letters 1999 , 40:6739-6743.

I21. Nanduri VB, Hanson RL, Goswami A, Wasylyk JM, LaPorte TL, Katipally K, Chung HJ and Patel RN: Biochemical approaches to the synthesis of ethyl 5-(S)-hydroxyhexanoate and 5-(S)hydroxyhexanenitrile. Enzyme and Microbial Technology 2001, 28:632-636.

122. Patel RN: Enzymatic synthesis of chiral intermediates for Omapatrilat, an antihypertensive drug. Biomolecular Engineering 200I, I7:167-182

123. Hanson RL, Howell JM, LaPorte TL, Donovan MJ, Cazzulino DL, Zannella V, Montana MA, Nanduri VB, Schwarz SR and Eiring RF, et al: Synthesis of allysine ethylene acetal using phenylalanine dehydrogenase from Thermoactinomyces intermedius. Enzyme and Microbial Technology 2000, 26:348-358.

124. Hanson RL, Schwinden MD, Baneriee A, Brzozowski DB, Chen BC Patel BP, Mcnamee CG, Kodersha GA, Kronenthal DR and Patel RN, et al: Enzymatic synthesis of L-6-hydroxynorleucine. Bioorganic \& Medicinal Chemistry 1999, 7:2247-2252.

125. Schmidt-Kastner G and Egerer P: Amino acids and peptides. Biotechnology Weinheim: Verlag Chemie: Kieslich K 1984 , 6a:387-419.

126. Nonconventional Yeasts in Biotechnology. A Handbook Berlin: Springer; 1996.

127. Porro D and Mattanovich D: Recombinant Protein Production in Yeasts. Methods in Molecular Biology Totowa, NJ, USA: Humana Press: Balbás P, Lorence A 2004, 24I-258.

128. Gellissen G: Heterologous protein production in methylotrophic yeasts. Applied Microbiology and Biotechnology 2000, 54:74I-750.

129. Hollenberg CP and Gellissen G: Production of recombinant proteins by methylotrophic yeasts. Current Opinion in Biotechnology 1997, 8:554-560.

130. Gellissen G and Hollenberg CP: Application of yeasts in gene expression studies: A comparison of Saccharomyces cerevisiae, Hansenula polymorpha and Kluyveromyces lactis - a review. Gene 1997, 190:87-97.

131. Hansen H and Hollenberg CP: Hansenula polymorpha (Pichio angusta). Nonconventional Yeasts in Biotechnology Heidelberg: Springer: Wolf K 1996, 293-311. 
132. Cereghino JL and Cregg JM: Heterologous protein expression in the methylotrophic yeast Pichia pastoris. Fems Microbiology Reviews 2000, 24:45-66.

133. Cregg JM, Cereghino JL, Shi JY and Higgins DR: Recombinant protein expression in Pichia pastoris. Molecular Biotechnology 2000, 16:23-52.

134. Sreekrishna K and Kropp K: Pichia pastoris. Nonconventional Yeasts in Biotechnology Heidelberg: Springer: Wolf K 1996, 203-252.

135. van Ooyen AJJ, Dekker P, Huang M, Olsthoorn MMA, Jacobs DI, Colussi PA and Taron $\mathrm{CH}$ : Heterologous protein production in the yeast Kluyveromyces lactis. Fems Yeast Research 2006, 6:38I-392.

136. Madzak C, Gaillardin C and Beckerich JM: Heterologous protein expression and secretion in the non-conventional yeast Yarrowia lipolytica : a review. Journal of Biotechnology 2004, 109:63-81.

137. Giga-Hama $Y$ and Kumagai $H$ : Expression system for foreign genes using the fission yeast Schizosaccharomyces pombe. Biotechnology and Applied Biochemistry 1999, 30:235-244.

138. Bailey JE: Toward A Science of Metabolic Engineering. Science 1991, 252: 1668-1675.

139. Cameron DC and Tong IT: Cellular and Metabolic Engineering - An Overview. Applied Biochemistry and Biotechnology 1993, 38: $105-140$

140. Stephanopoulos G: Metabolic fluxes and metabolic engineering. Metabolic Engineering 1999, I:I-II.

141. Ostergaard S, Olsson L and Nielsen J: Metabolic engineering of Saccharomyces cerevisiae. Microbiology and Molecular Biology Reviews 2000, 64:34.

142. Nielsen J: Metabolic engineering. Applied Microbiology and Biotechnology 200I, 55:263-283.

143. Stephanopoulos GN, Aristidou AA and Nielsen J: Metabolic Engineering: Principles and Methodologies San Diego: Academic Press; 1998.

144. Lee SY and Papoutsakis ET: Metabolic engineering New York: Marcel Dekker, Inc; 1999.

145. Werpy T, Petersen G, Aden A, Bozell J, Holladay J, White J, Manheim A, Elliot D, Lasure $L$ and Jones $S$, et al: Results of screening for potential candidates from sugars and synthesis gas. Top value added chemicals from biomass Washington, DC: U.S. Department of Energy: Werpy T, Petersen G 2004, 76.

146. Zaldivar J, Nielsen J and Olsson L: Fuel ethanol production from lignocellulose: a challenge for metabolic engineering and process integration. Applied Microbiology and Biotechnology 200 I, 56: $17-34$

147. Hahn-Haegerdal B, Karhumaa K, Fonseca C, Spencer-Martins I and Gorwa-Grauslund MF: Towards industrial pentose-fermenting yeast strains. Applied Microbiology and Biotechnology 2007, 74:937-953

148. Hahn-Haegerdal B, Karhumaa K, Jeppsson $M$ and GorwaGrauslund MF: Metabolic engineering for pentose utilization in Saccharomyces cerevisiae. Biofuels Berlin, Heidelberg: Springer; 2007, 147-177.

149. Kim MD, Jeun YS, Kim SG, Ryu YW and Seo JH: Comparison of xylitol production in recombinant Saccharomyces cerevisiae strains harboring XYL I gene of Pichia stipitis and GRE3 gene of S. cerevisiae. Enzyme and Microbial Technology 2002, 3 I:862-866.

150. Granstroem TB, Izumori $K$ and Leisola M: A rare sugar xylitol. Part I: the biochemistry and biosynthesis of xylitol. Applied Microbiology and Biotechnology 2007, 74:277-28I.

15I. Shieh WR, Gopalan AS and Sih C): Stereochemical Control of Yeast Reductions 5. Characterization of the Oxidoreductases Involved in the Reduction of Beta-Keto-Esters. Journal of the American Chemical Society 1985, 107:2993-2994.

152. Rodriguez S, Kayser MM and Stewart JD: Highly stereoselective reagents for beta-keto ester reductions by genetic engineering of baker's yeast. Journal of the American Chemical Society 200 I, 123:1547-1555

153. Katz M, Hahn-Haegerdal B and Gorwa-Grauslund MF: Screening of two complementary collections of Saccharomyces cerevisiae to identify enzymes involved in stereo-selective reductions of specific carbonyl compounds: an alternative to protein purification. Enzyme and Microbial Technology 2003, 33:163-172.

154. Johanson T, Katz M and Gorwa-Grauslund MF: Strain engineering for stereoselective bioreduction of dicarbonyl compounds by yeast reductases. Fems Yeast Research 2005, 5:5 I3-525.

155. Johanson T, Carlquist M, Olsson C, Rudolf A, Frejd T and GorwaGrauslund MF: Reaction and strain engineering for improved stereo-selective whole-cell reduction of a bicyclic diketone. Applied Microbiology and Biotechnology 2008, 77: I I I I-I I I8.
156. Almqvist F, Torstensson L, Gudmundsson A and Frejd T: New ligands for the titanium(IV)-induced asymmetric reduction of ketones with catecholborane. Angewandte Chemie-International Edition in English 1997, 36:376-377.

157. Mori K and Nagano E: Preparative bioorganic chemistry. Part 10. Asymmetric reductions of bicyclo[2.2.2] diones with baker's yeast. Biocatalysis 1990, 3:25-36.

I58. Kratzer R, Egger S and Nidetzky B: Integration of enzyme, strain and reaction engineering to overcome limitations of baker's yeast in the asymmetric reduction of $\alpha$-keto esters. Biotechnology and Bioengineering 2008, 101002/bit.21980.

159. Kratzer R and Nidetzky B: Identification of Candida tenuis xylose reductase as highly selective biocatalyst for the synthesis of aromatic alpha-hydroxy esters and improvement of its efficiency by protein engineering. Chemical Communications 2007, 1047-1049.

160. Farhi M, Dudareva N, Masci T, Weiss D, Vainstein A and Abeliovich $\mathrm{H}$ : Synthesis of the food flavoring methyl benzoate by genetically engineered Saccharomyces cerevisiae. Journal of Biotechnology 2006, 1 22:307-315.

161. González-Candelas L, Gil JV, Lamuela-Raventós RM and Ramón D: The use of transgenic yeasts expressing a gene encoding a glycosyl-hydrolase as a tool to increase resveratrol content in wine. International Journal of Food Microbiology 2000, 59:179-I83.

162. Jang MS, Cai EN, Udeani GO, Slowing KV, Thomas CF, Beecher CWW, Fong HHS, Farnsworth NR, Kinghorn AD and Mehta RG, et al: Cancer chemopreventive activity of resveratrol, a natural product derived from grapes. Science 1997 , 275:218-220.

163. Subbaramaiah K, Chung WJ, Michaluart P, Telang N, Tanabe T, Inoue H, Jang MS, Pezzuto JM and Dannenberg AJ: Resveratrol inhibits cyclooxygenase- 2 transcription and activity in phorbol ester-treated human mammary epithelial cells. Journal of Biological Chemistry 1998, 273:21875-21882.

164. Genoves S, Gil JV, Manzanares P, Aleixandre JL and Valles S: Candida molischiana beta-glucosidase production by Saccharomyces cerevisiae and its application in winemaking. Journal of Food Science 2003, 68:2096-2100.

165. Smit A, Otero RRC, Lambrechts MG, Pretorius IS and Van Rensburg P: Enhancing volatile phenol concentrations in wine by expressing various phenolic acid decarboxylase genes in Saccharomyces cerevisiae. Journal of Agricultural and Food Chemistry 2003, 5 I:4909-49I5.

166. Cordente AG, Swiegers JH, Hegardt FG and Pretorius IS: Modulating aroma compounds during wine fermentation by manipulating carnitine acetyltransferases in Saccharomyces cerevisiae. Fems Microbiology Letters 2007, 267:159-166.

167. Stewart JD, Reed KW and Kayser MM: 'Designer yeast': A new reagent for enantioselective Baeyer-Villiger oxidations. Journal of the Chemical Society-Perkin Transactions I 1996, 755-757.

168. Stewart JD, Reed KW, Martinez CA, Zhu J, Chen G and Kayser MM Recombinant baker's yeast as a whole-cell catalyst for asymmetric Baeyer-Villiger oxidations. Journal of the American Chemical Society 1998, 120:354I-3548.

169. Stewart JD, Reed KW, Zhu J, Chen G and Kayser MM: A “designer yeast" that catalyzes the kinetic resolutions of 2-alkylsubstituted cyclohexanones by enantioselective BaeyerVilliger oxidations. Journal of Organic Chemistry 1996, 6 I:7652-7653

170. Kayser MM, Chen G and Stewart JD: Enantio- and regioselective Baeyer-Villiger oxidations of 2- and 3-substituted cyclopentanones using engineered bakers' yeast. Journal of Organic Chemistry 1998, 63:7103-7106.

17I. Lee EY, Yoo SS, Kim HS, Lee SJ, Oh YK and Park S: Production of (S)-styrene oxide by recombinant Pichia pastoris containing epoxide hydrolase from Rhodotorula glutinis. Enzyme and Microbial Technology 2004, 35:624-63I.

172. Hakki T, Zearo S, Dragan CA, Bureik $M$ and Bernhardt R: Coexpression of redox partners increases the hydrocortisone (cortisol) production efficiency in CYP I I B I expressing fission yeast Schizosaccharomyces pombe. Journal of Biotechnology 2008, 133:35I-359.

173. Peters FT, Dragan CA, Wilde DR, Meyer MR, Zapp J, Bureik M and Maurer $\mathrm{HH}$ : Biotechnological synthesis of drug metabolites using human cytochrome P450 2D6 heterologously expressed in fission yeast exemplified for the designer drug metabolite 4 '-hydroxymethyl-alpha-pyrrolidinobutyrophenone. Biochemical Pharmacology 2007, 74:5II-520. 
174. Leonida MD: Redox enzymes used in chiral syntheses coupled to coenzyme regeneration. Current Medicinal Chemistry 200I, 8:345-369.

175. Donk van der WA and Zhao HM: Recent developments in pyridine nucleotide regeneration. Current Opinion in Biotechnology 2003, I 4:42I-426.

176. Endo $T$ and Koizumi S: Microbial conversion with cofactor regeneration using genetically engineered bacteria. Advanced Synthesis \& Catalysis 2001, 343:52 I-526.

177. Zhao HM and Donk van der WA: Regeneration of cofactors for use in biocatalysis. Current Opinion in Biotechnology 2003, 14:583-589.

178. Nissen TL, Anderlund M, Nielsen J, Villadsen J and KiellandBrandt MC: Expression of a cytoplasmic transhydrogenase in Saccharomyces cerevisiae results in formation of 2oxoglutarate due to depletion of the NADPH pool. Yeast 2001, I 8:19-32.

179. Bruinenberg PM, Vandijken JP and Scheffers WA: A theoretical analysis of NADPH production and consumption in yeasts. Journal of General Microbiology 1983, I 29:953-964.

180. Bruinenberg PM, Vandijken JP and Scheffers WA: An enzymic analysis of NADPH production and consumption in Candida utilis. Journal of General Microbiology 1983, I 29:965-97I.

18I. Anderlund M, Nissen TL, Nielsen J, Villadsen J, Rydstrom J, HahnHagerdal B and Kielland-Brandt MC: Expression of the Escherichia coli pntA and pntB genes, encoding nicotinamide nucleotide transhydrogenase, in Saccharomyces cerevisiae and its effect on product formation during anaerobic glucose fermentation. Applied and Environmental Microbiology 1999, 65:2333-2340.

182. dos Santos MM, Thygesen G, Kotter P, Olsson L and Nielsen J: Aerobic physiology of redox-engineered Saccharomyces cerevisiae strains modified in the ammonium assimilation for increased NADPH availability. Fems Yeast Research 2003, 4:59-68.

183. Nissen TL, Kielland-Brandt MC, Nielsen J and Villadsen J: Optimization of ethanol production in Saccharomyces cerevisiae by metabolic engineering of the ammonium assimilation. Metabolic Engineering 2000, 2:69-77.

184. Heux S, Cachon $R$ and Dequin S: Cofactor engineering in Saccharomyces cerevisiae : Expression of a H2O-forming NADH oxidase and impact on redox metabolism. Metabolic Engineering 2006, 8:303-3i4.

185. Fukuda $Y$, Yamaguchi S, Hashimoto $H$, Shimosaka $M$ and Kimura A: Cloning of Glucose Phosphorylating Genes in S. cerevisiae by the Ku-Method and Application to ATP Production. Agricultural and Biological Chemistry 1984, 48:2877-288I.

186. Chen RRZ: Permeability issues in whole-cell bioprocesses and cellular membrane engineering. Applied Microbiology and Biotechnology 2007, 74:730-738.

187. Liu $Y$, Hama H, Fujita $Y$, Kondo A, Inoue $Y$, Kimura $A$ and Fukuda $H$ : Production of $S$-lactoylglutathione by high activity whole cell biocatalysts prepared by permeabilization of recombinant Saccharomyces cerevisiae with alcohols. Biotechnology and Bioengineering 1999, 64:54-60.

188. Lee YJ, Kim CS and Oh DK: Lactulose production by betagalactosidase in permeabilized cells of Kluyveromyces lactis. Applied Microbiology and Biotechnology 2004, 64:787-793.

189. Kubal BS and D'Souza SF: Immobilization of catalase by entrapment of permeabilized yeast cells in hen egg white using glutaraldehyde. Journal of Biochemical and Biophysical Methods 2004, 59:61-64.

190. Upadhya R, Nagajyothi and Bhat SG: Stabilization of D-amino acid oxidase and catalase in permeabilized Rhodotorula gracilis cells and its application for the preparation of alphaketoacids. Biotechnology and Bioengineering 2000, 68:430-436.

191. Isoai A, Kimura H, Reichert A, Schorgendorfer K, Nikaido $K$, Tohda H, Giga-Hama $Y$, Mutoh $N$ and Kumagai $H$ : Production of D-amino acid oxidase (DAO) of Trigonopsis variabilis in Schizosaccharomyces pombe and the characterization of biocatalysts prepared with recombinant cells. Biotechnology and Bioengineering 2002, 80:22-32.

192. Matsumoto T, Takahashi S, Kaieda M, Ueda M, Tanaka A, Fukuda H and Kondo A: Yeast whole-cell biocatalyst constructed by intracellular overproduction of Rhizopus oryzae lipase is applicable to biodiesel fuel production. Applied Microbiology and Biotechnology 200I, 57:515-520.

193. Fontanille $P$ and Larroche $C$ : Optimization of isonovalal production from alpha-pinene oxide using permeabilized cells of Pseudomonas rhodesiae CIP I 0749I. Applied Microbiology and Biotechnology 2003, 60:534-540.

194. Schreuder MP, Mooren ATA, Toschka HY, Verrips CT and Klis FM: Immobilizing proteins on the surface of yeast cells. Trends in Biotechnology 1996, I4: II5-120.

195. Shimazu M, Mulchandani $A$ and Chen W: Cell surface display of organophosphorus hydrolase using ice nucleation protein. Biotechnology Progress 200I, 17:76-80.

196. Fukuda $T$, Isogawa $D$, Takagi $M$, Kato-Murai $M$, Kimoto $H$, Kusaoke $H$, Ueda $M$ and Suye SI: Yeast cell-surface expression of chitosanase from Paenibacillus fukuinensis. Bioscience Biotechnology and Biochemistry 2007, 71:2845-2847.

197. Matsumoto T, Ito $M$, Fukuda $H$ and Kondo A: Enantioselective transesterification using lipase-displaying yeast whole-cell biocatalyst. Applied Microbiology and Biotechnology 2004, 64:48I-485.

198. Matsumoto T, Fukuda $H$, Ueda $M$, Tanaka $A$ and Kondo $A$ : Construction of yeast strains with high cell surface lipase activity by using novel display systems based on the Flo Ip flocculation functional domain. Applied and Environmental Microbiology 2002, 68:4517-4522.

199. Nakamura $\mathrm{Y}$, Matsumoto T, Nomoto F, Ueda M, Fukuda $\mathrm{H}$ and Kondo A: Enhancement of activity of lipase-displaying yeast cells and their application to optical resolution of $(R, S)$ - I benzyloxy-3-chloro-2-propyl monosuccinate. Biotechnology Progress 2006, 22:998-1002.

200. Shibamoto H, Matsumoto T, Fukuda $H$ and Kondo A: Molecular engineering of Rhizopus oryzae lipase using a combinatorial protein library constructed on the yeast cell surface. Journal of Molecular Catalysis B: Enzymatic 2004, 28:235-239.

201. Kaya M, Ito J, Kotaka A, Matsumura K, Bando H, Sahara H, Ogino $C$ Shibasaki S, Kuroda $\mathrm{K}$ and Ueda $\mathrm{M}$, et al: Isoflavone aglycones production from isoflavone glycosides by display of betaglucosidase from Aspergillus oryzae on yeast cell surface. Applied Microbiology and Biotechnology 2008, 79:5I-60.

202. Kim HJ, Lee JH, Kim HC, Lee JW, Kim YH and Nam SW: Characterization of cyclofructans from inulin by Saccharomyces cerevisiae strain displaying cell-surface cycloinulooligosaccharide fructanotransferase. Journal of Microbiology and Biotechnology 2007, I 7:695-700.

203. Lipovsek D, Antipov E, Armstrong KA, Olsen MI, Klibanov AM, Tidor B and Wittrup KD: Selection of horseradish peroxidase variants with enhanced enantioselectivity by yeast surface display. Chemistry \& Biology 2007, | 4: | | 76-| |85.

204. Kato M, Fuchimoto J, Tanino T, Kondo A, Fukuda $\mathrm{H}$ and Ueda $\mathrm{M}$ Preparation of a whole-cell biocatalyst of mutated Candida antarctica lipase B (mCALB) by a yeast molecular display system and its practical properties. Applied Microbiology and Biotechnology 2007, 75:549-555.

205. Zhang NY, Suen WC, Windsor W, Xiao L, Madison V and Zaks A: Improving tolerance of Candida antarctica lipase B towards irreversible thermal inactivation through directed evolution. Protein Engineering 2003, 16:599-605.

206. Ueda $M$ and Tanaka $A$ : Cell surface engineering of yeast: Construction of arming yeast with biocatalyst. Journal of Bioscience and Bioengineering 2000, 90:125-136.

207. $\mathrm{Wu} \mathrm{CH}$, Mulchandani A and Chen W: Versatile microbial surface-display for environmental remediation and biofuels production. Trends in Microbiology 2008, 16:181-188.

208. Fujita Y, Katahira S, Ueda M, Tanaka A, Okada H, Morikawa Y, Fukuda $\mathrm{H}$ and Kondo $\mathrm{A}$ : Construction of whole-cell biocatalyst for xylan degradation through cell-surface xylanase display in Saccharomyces cerevisiae. Journal of Molecular Catalysis B: Enzymatic 2002, I7:189-195.

209. Fujita $Y$, Ito J, Ueda M, Fukuda $H$ and Kondo A: Synergistic saccharification, and direct fermentation to ethanol, of amorphous cellulose by use of an engineered yeast strain codisplaying three types of cellulolytic enzyme. Applied and Environmental Microbiology 2004, 70:1207-1212.

210. Fleet GH: Cell walls. The Yeasts. Yeasts Organelles London: Academic Press: Rose AH, Harrison JS 21991, 4:199-278.

211. Klis FM: Cell-Wall Assembly in Yeast. Yeast 1994, 10:851-869.

212. Jiang ZB, Gao B, Ren R, Tao XY, Ma YS and Wei DZ: Efficient display of active lipase LipB52 with a Pichia pastoris cell surface display system and comparison with the LipB52 displayed on Saccharomyces cerevisiae cell surface. Bmc Biotechnology 2008, 8

213. Yue LX, Chi ZM, Wang L, Liu J, Madzak C, Li J and Wang XG: Construction of a new plasmid for surface display on cells of 
Yarrowia lipolytica. Journal of Microbiological Methods 2008, 72: $116-123$

214. O'Hagan D: The Polyketide Metabolites Chichester, UK: Ellis Horwood; 1991.

215. Mutka SC, Bondi SM, Carney JR, Da Silva NA and Kealey JT: Metabolic pathway engineering for complex polyketide biosynthesis in Saccharomyces cerevisiae. Fems Yeast Research 2006, 6:40-47.

216. Misawa N, Nakagawa M, Kobayashi K, Yamano S, Izawa $Y$, Nakamura $K$ and Harashima $K$ : Elucidation of the Erwinia uredovora carotenoid biosynthetic pathway by functional analysis of gene products expressed in Escherichia coli. Journal of Bacteriology 1990, 172:6704-6712.

217. Misawa N, Satomi Y, Kondo K, Yokoyama A, Kajiwara S, Saito T, Ohtani $T$ and Miki W: Structure and functional analysis of a marine bacterial carotenoid biosynthesis gene cluster and astaxanthin biosynthetic pathway proposed at the gene level. Journal of Bacteriology 1995, 177:6575-6584.

218. Shimada H, Kondo K, Fraser PD, Miura Y, Saito T and Misawa N: Increased carotenoid production by the food yeast Candida utilis through metabolic engineering of the isoprenoid pathway. Applied and Environmental Microbiology 1998, 64:2676-2680.

219. Miura Y, Kondo K, Saito T, Shimada H, Fraser PD and Misawa N: Production of the carotenoid lycopene, beta-carotene, and astaxanthin in the food yeast Candida utilis. Applied and Environmental Microbiology 1998, 64:1226-1229.

220. Misawa $\mathrm{N}$ and Shimada $\mathrm{H}$ : Metabolic engineering for the production of carotenoids in non-carotenogenic bacteria and yeasts. Journal of Biotechnology 1998, 59:169-181.

221. Yamano S, Ishii T, Nakagawa M, Ikenaga $\mathrm{H}$ and Misawa N: Metabolic engineering for production of beta-carotene and lycopene in Saccharomyces cerevisiae. Bioscience Biotechnology and Biochemistry 1994, 58: I| I2-III4.

222. Ausich RL, Brinkhaus FL, Mukharji I, Proffitt JH, Yarger JG and Yen HCB: Biosynthesisof carotenoids in genetically engineered hosts. (WO 9113078) 1991, 311, 4-3-1991.

223. Ausich RL: Production of Carotenoids by Recombinant DNA Technology. Pure and Applied Chemistry 1994, 66:1057-1062.

224. Daum G, Lees ND, Bard M and Dickson R: Biochemistry, cell biology and molecular biology of lipids of Saccharomyces cerevisiae. Yeast 1998, 14:|47|-1510.

225. Dimster-Denk D, Rine J, Phillips J, Scherer S, Cundiff P, DeBord K, Gilliland D, Hickman S, Jarvis A and Tong L, et al: Comprehensive evaluation of isoprenoid biosynthesis regulation in Saccharomyces cerevisiae utilizing the Genome Reporter Matrix (TM). Journal of Lipid Research 1999, 40:850-860.

226. Ro DK, Paradise EM, Ouellet M, Fisher KJ, Newman KL, Ndungu JM, Ho KA, Eachus RA, Ham TS and Kirby J, et al: Production of the antimalarial drug precursor artemisinic acid in engineered yeast. Nature 2006, 440:940-943.

227. Shiba Y, Paradise EM, Kirby J, Ro D-K and Keasling JD: Engineering of the pyruvate dehydrogenase bypass in Saccharomyces cerevisiae for high-level production of isoprenoids. Metabolic Engineering 2007, 9:160-168.

228. Szczebara FM, Chandelier C, Villeret C, Masurel A, Bourot S, Duport C, Blanchard S, Groisillier A, Testet E and Costaglioli P, et al: Total biosynthesis of hydrocortisone from a simple carbon source in yeast. Nature Biotechnology 2003, 21:143-149.

229. Jackson BE, Hart-Wells EA and Matsuda SPT: Metabolic engineering to produce sesquiterpenes in yeast. Organic Letters 2003, 5:1629-1632.

230. Dejong JM, Liu YL, Bollon AP, Long RM, Jennewein S, Williams D and Croteau RB: Genetic engineering of Taxol biosynthetic genes in Saccharomyces cerevisiae. Biotechnology and Bioengineering 2006, 93:212-224.

23I. Wattanachaisaereekul S, Lantz AE, Nielsen ML, Andresson OS and Nielsen J: Optimization of heterologous production of the polyketide 6-MSA in Saccharomyces cerevisiae. Biotechnology and Bioengineering 2007, 97:893-900.

232. Kealey JT, Liu L, Santi DV, Betlach MC and Barr PJ: Production of a polyketide natural product in nonpolyketide-producing prokaryotic and eukaryotic hosts. Proceedings of the National Academy of Sciences of the United States of America 1998, 95:505-509.

233. Ro DK and Douglas CJ: Reconstitution of the entry point of plant phenylpropanoid metabolism in yeast (Saccharomyces cerevisiae) - Implications for control of metabolic flux into the phenylpropanoid pathway. Journal of Biological Chemistry 2004, 279:2600-2607.
234. Vannelli T, Qi WW, Sweigard J, Gatenby AA and Sariaslani FS: Production of $p$-hydroxycinnamic acid from glucose in Saccharomyces cerevisiae and Escherichia coli by expression of heterologous genes from plants and fungi. Metabolic Engineering 2007, 9:|42-151.

235. Jiang $H X$, Wood KV and Morgan JA: Metabolic engineering of the phenylpropanoid pathway in Saccharomyces cerevisiae. Applied and Environmental Microbiology 2005, 71:2962-2969.

236. Beekwilder J, Meer van der IM, Sibbesen O, Broekgaarden M, Ovist I, Mikkelsen JD and Hall RD: Microbial production of natural raspberry ketone. Journal of Biotechnology 2007, 2:1270-1279.

237. Larsen M, Poll L, Callesen O and Lewis M: Relations Between the Content of Aroma Compounds and the Sensory Evaluation of 10 Raspberry Varieties (Rubus Idaeus L). Acta Agriculturae Scandinavica | 991, 4I:447-454.

238. Becker JVW, Armstrong GO, Merwe Van der MJ, Lambrechts MG, Vivier MA and Pretorius IS: Metabolic engineering of Saccharomyces cerevisiae for the synthesis of the wine-related antioxidant resveratrol. Fems Yeast Research 2003, 4:79-85.

239. Beekwilder J, Wolswinkel R, Jonker H, Hall R, De Vos CHR and Bovy A: Production of resveratrol in recombinant microorganisms. Applied and Environmental Microbiology 2006 72:5670-5672

240. Branduardi P, Fossati T, Sauer M, Pagani R, Mattanovich D and Porro D: Biosynthesis of vitamin $C$ by yeast leads to increased stress resistance. PLOS ONE 2007, 2: el 092.

24I. Duport C, Spagnoli R, Degryse E and Pompon D: Self-sufficient biosynthesis of pregnenolone and progesterone in engineered yeast. Nature Biotechnology 1998, 16:186-189.

242. Crowley JH, Leak FW, Shianna KV, Tove S and Parks LW: A mutation in a purported regulatory gene affects control of sterol uptake in Saccharomyces cerevisiae. Journal of Bacteriology 1998, 180:4177-4|83

243. Gokhale RS, Hunziker D, Cane DE and Khosla C: Mechanism and specificity of the terminal thioesterase domain from the erythromycin polyketide synthase. Chemistry \& Biology 1999, 6:117-125.

244. Regentin R, Kennedy J, Wu N, Carney JR, Licari P, Galazzo J and Desai R: Precursor-directed biosynthesis of novel triketide lactones. Biotechnology Progress 2004, 20:122-127.

245. Hani J and Feldmann H: tRNA genes and retroelements in the yeast genome. Nucleic Acids Research 1998, 26:689-696.

Publish with BioMed Central and every scientist can read your work free of charge

"BioMed Central will be the most significant development for disseminating the results of biomedical research in our lifetime. "

Sir Paul Nurse, Cancer Research UK

Your research papers will be:

- available free of charge to the entire biomedical community

- peer reviewed and published immediately upon acceptance

- cited in PubMed and archived on PubMed Central

- yours - you keep the copyright

Submit your manuscript here:

http://www.biomedcentral.com/info/publishing_adv.asp
BioMedcentral 